LA-14191-T

Thesis

Approved for public release;

distribution is unlimited.

\title{
An Analytic Tool to Investigate the \\ Effect of Binder on the Sensitivity of \\ HMX-Based Plastic Bonded Explosives
} in the Skid Test

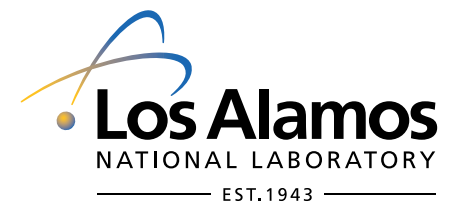

The World's Greatest Science Protecting America 
This thesis was accepted by the Department of Mechanical Engineering, New Mexico Institute of Mining and Technology, Socorro, New Mexico, in partial fulfillment of the requirements for the degree of Master of Science. The text and illustrations are the independent work of the author and only the front matter has been edited by the IM-1 Writing and Editing Staff to conform with Department of Energy and Los Alamos National Laboratory publication policies.

Los Alamos National Laboratory, an affirmative action/equal opportunity employer, is operated by the University of California for the United States Department of Energy under contract W-7405-ENG-36.

This report was prepared as an account of work sponsored by an agency of the United States Government. Neither the Regents of the University of California, the United States Government nor any agency thereof, nor any of their employees make any warranty, express or implied, or assume any legal liability or responsibility for the accuracy, completeness, or usefulness of any information, apparatus, product, or process disclosed, or represent that its use would not infringe privately owned rights. Reference herein to any specific commercial product, process, or service by trade name, trademark, manufacturer, or otherwise does not necessarily constitute or imply its endorsement, recommendation, or favoring by the Regents of the University of California, the United States Government, or any agency thereof. The views and opinions of authors expressed herein do not necessarily state or reflect those of the Regents of the University of California, the United States Government, or any agency thereof. Los Alamos National Laboratory strongly supports academic freedom and a researcher's right to publish; as an institution, however, the Laboratory does not endorse the viewpoint of a publication or guarantee its technical correctness. 
LA-14191-T

Thesis

Issued: February 2005

An Analytic Tool to Investigate the

Effect of Binder on the Sensitivity of

HMX-Based Plastic Bonded Explosives

in the Skid Test

David J. Hayden 



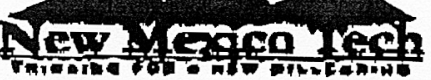

OFTICE OF GRADUATE STUDIES

MATTERS DEGREE ADVISORY COMMATTEE

Name David I. Hayden

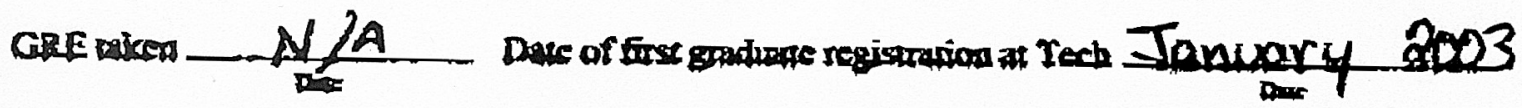

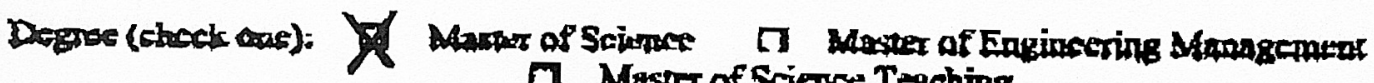

(1) Mascer of Ecience Teaching

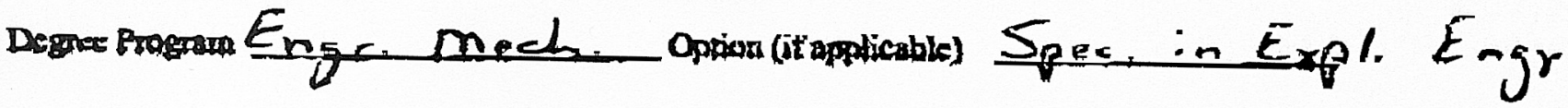

D Thesis Dindepandan Smdy

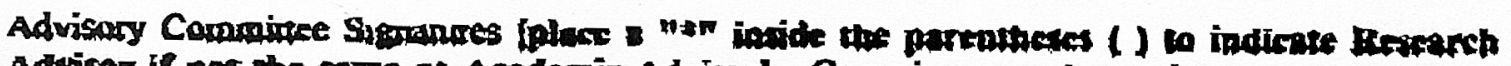

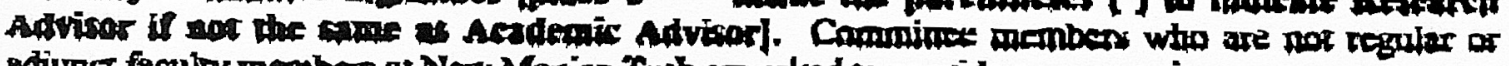
adjuner feculizy meanbess at New Merico Tech are asked to prowide a farregr yira.

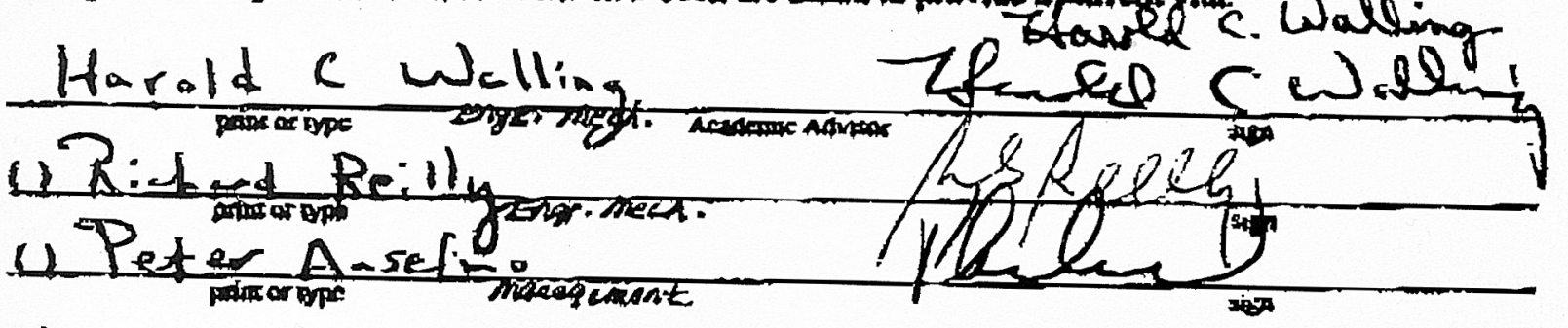

1

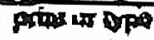

(1)

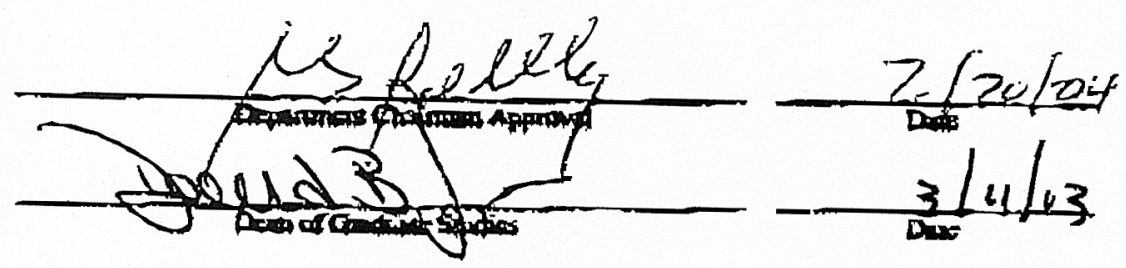

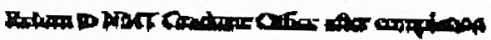

pacos 


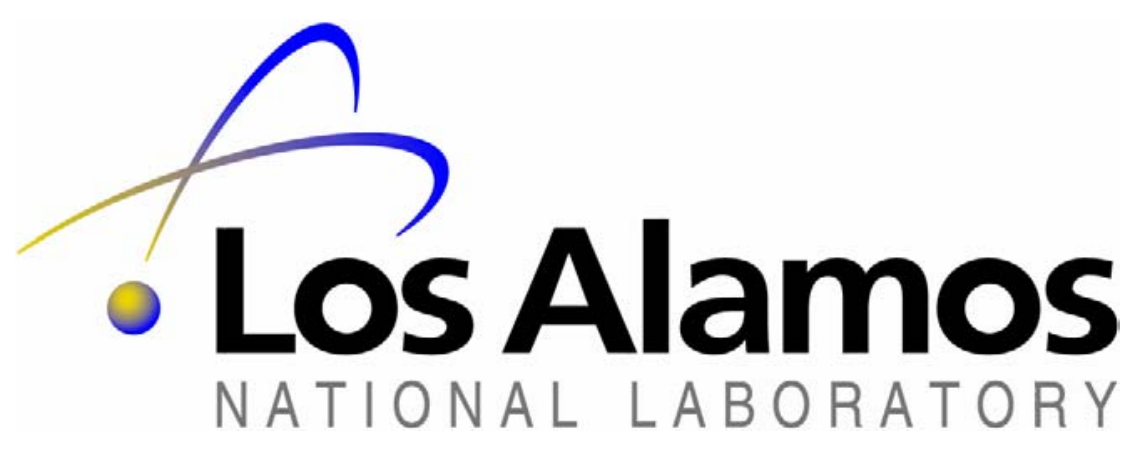

\author{
AN ANALYTIC TOOL TO \\ INVESTIGATE THE EFFECT OF \\ BINDER ON THE SENSITIVITY OF \\ HMX BASED PLASTIC BONDED \\ EXPLOSIVES IN THE SKID-TEST
}

\author{
By \\ David J. Hayden \\ ESA-MEE
}

November 2004

ES-590 Independent Study Report 


\section{ABSTRACT}

This project will develop an analytical tool to calculate performance of HMX based PBXs in the skid test. The skid-test is used as a means to measure sensitivity for large charges in handling situations. Each series of skid tests requires dozens of drops of large billets. It is proposed that the reaction (or lack of one) of PBXs in the skid test is governed by the mechanical properties of the binder. If true, one might be able to develop an analytical tool to estimate skid test behavior for new PBX formulations. Others over the past 50 years have tried to develop similar models. This project will research and summarize the works of others and couple the work of 3 into an analytical tool that can be run on a PC to calculate drop height of HMX based PBXs.

Detonation due to dropping a billet is argued to be a dynamic thermal event. To avoid detonation, the heat created due to friction at impact, must be conducted into the charge or the target faster than the chemical kinetics can create additional energy. The methodology will involve numerically solving the Frank-Kamenetskii equation in one dimension. The analytical problem needs to be bounded in terms of how much heat is introduced to the billet and for how long. Assuming an inelastic collision with no rebound, the billet will be in contact with the target for a short duration determined by the equations of motion. For the purposes of the calculations, it will be assumed that if a detonation is to occur, it will transpire within that time. The surface temperature will be raised according to the friction created using the equations of motion of dropping the billet on a rigid surface.

The study will connect the works of Charles Anderson ${ }^{(8)}$, Alan Randolph, Larry Hatler, Alfonse Popolato ${ }^{(1)}$, and Charles Mader $^{(2)}$ into a single PC based analytic tool. Anderson's equations of motion will be used to calculate the temperature rise upon impact, the time this temperature is maintained (contact time) will be obtained from the work of Hatler et. al., and the reactive temperature rise will be obtained from Mader's work. Finally, the assessment of when a detonation occurs will be derived from Bowden and Yoffe's ${ }^{(3)}$ thermal explosion theory (hot spot). 


\section{TABLE OF CONTENTS}

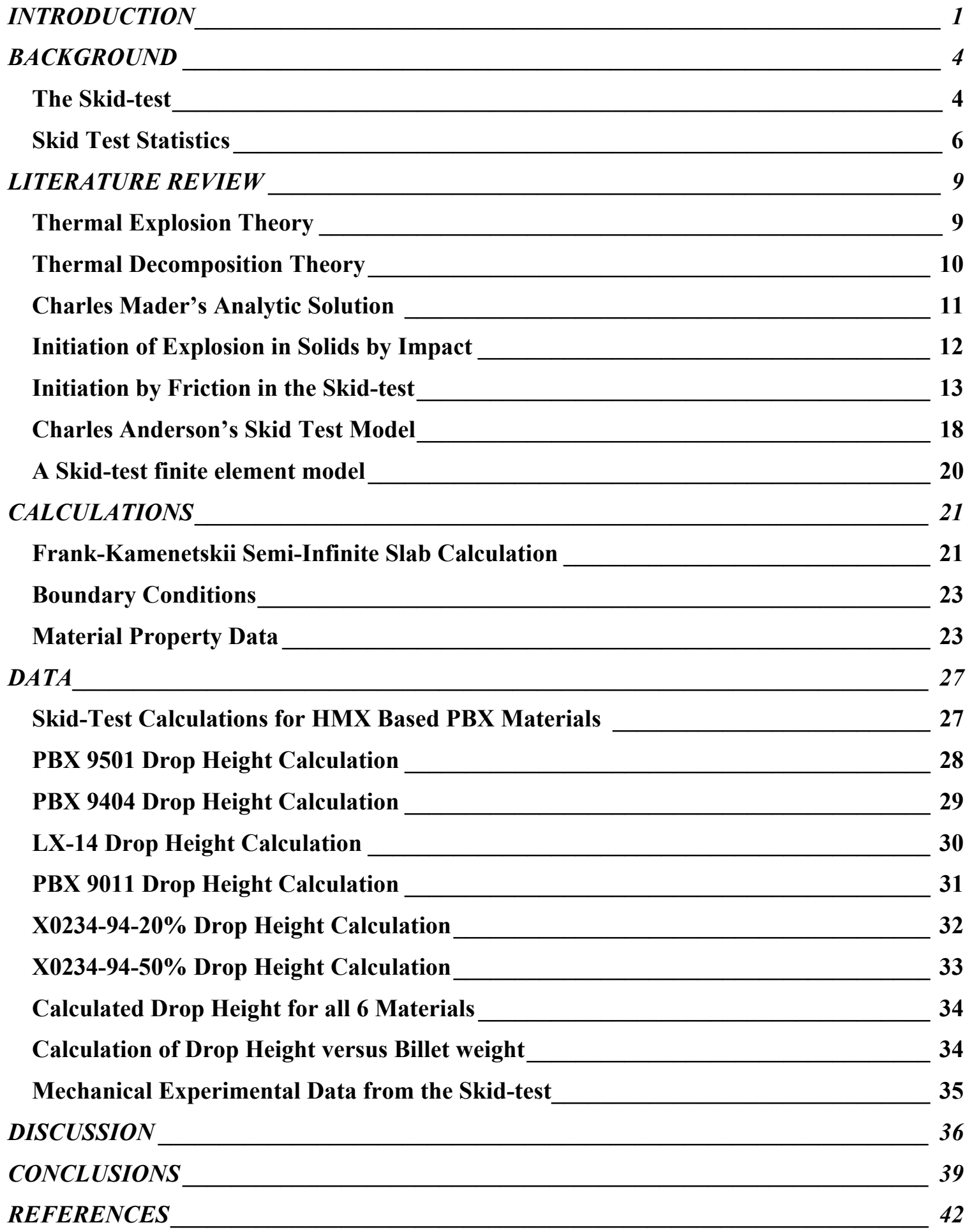




\section{LIST OF FIGURES}

Figure 1 Wire Guided Free-Fall Skid Test __ 5

Figure 2 LANL Skid Test Summary ___ 5

Figure 3 Pendulum Skid Test Configuration __ 6

Figure 4 Billet Dynamics, Just Before \& at Impact __ 15

Figure 5 Skid Test Sensitivity vs Mat'l Strength for HMX based Mat'ls___ 18

Figure 6 Frank-Kamenetskii Semi-Infinite Slab Calculation _ 22

Figure 7 Hopkinson Bar Data for PBX $9404 \ldots 25$

Figure 8 Hopkinson Bar Data for PBX 9011 _ 26

Figure 9 PBX 9501 Temperature time history__ 28

Figure 11 LX-14 Temperature time history__ 30

Figure 12 PBX 9011 Temperature time history____ 31

Figure 13 X0234-94-20\% Temperature time history___ 32

Figure 14 X0234-94-50\% Temperature time history___ 33

Figure 15 Calculated Drop Heights for HMX Based PBXS__ 34

Figure 16 Effect of Billet Size on Drop Height of PBX $9501 \_35$

Figure 17 Pantex Skid-test Mechanical Impact Data ${ }^{(15)}{ }_{2} \quad 36$ 


\section{LIST OF TABLES}

Table 1 Dynamic Eqns, Oblique Impact of PBX Hemisphere on Rigid Target_ 18

Table 2 HMX Based PBX Material Properties 27

Table 3 Impact Sensitivity Rank Ordering of HMX Based PBXs 40 


\section{INTRODUCTION}

High Explosives are a tool that can be used in many areas of research and are a critical component in both conventional and nuclear weapons. However, to be useful in most of these applications, the explosives must be fabricated into precise configurations. Engineers have made use of TNT for nearly a century as a safe and inexpensive material from which to fabricate precision components. TNT holds a unique physical property, it melts at a temperature well below any exothermic reaction. Casting of TNT became quite a technology in mid to late 1900s. TNT was cast and machined and used extensively in weapons and as a hi-strain rate experimental tool (plane wave lens for example). TNT is also relatively insensitive when compared with other secondary explosives. Along the way, many alloys of TNT were developed to improve certain properties. For instance, Aluminum has been added to improve brisance, and RDX has been added to other alloys to increase energy. TNT can be cast to a density of 1.62 or about $98 \%$ of TMD; it can also be pressed to the same densities. However, in the ever-increasing optimization of weapons, TNT falls short in energy content. The desire is to pack more energy into smaller volumes that led to the development of Plastic Bonded Explosives (PBX).

Many PBXs have been developed over the past half-century, all generally with the goal of providing an engineering material for a specific or broad range of applications. Pure explosive crystals are of little use to the physicist or engineer because in almost all applications, the goal is to pack as much HE into a given space as possible (high density). For obvious reasons, loose $\mathrm{HE}$ crystals do not lend themselves to high density packing. However, when the HE crystals are coated with a polymer binder, the raw material becomes very useful for manufacturing explosive components. The focus of this paper is the nuclear weapon PBXs and in particular those utilizing HMX.

Manufacturing of explosive components is a niche field of engineering that uses knowledge, theory, and practices typical with more traditional materials. PBXs are taken from their pure crystalline state, to a plastic bonded "prill form". The prills are a conglomeration of hundreds of crystals in a matrix of plastic binder. PBX materials are usually a bi-modal or 
tri-modal mixture of explosive crystals, meaning there are two or three nominal particle sizes with a specified distribution about the means. Prills range in size from $0.1-2 \mathrm{~mm}$.

Prior to pressing, machining, casting, etc., a material must be evaluated to understand its fundamental safety behavior. Most of these tests are small scale and use tens of milligrams to a gram of material. Tests such as drop weight impact, spark (ESD), friction, DSC, and Vacuum stability are used to rank order new explosives with other known materials. These tests however are not an absolute measure of how a large consolidate billet of material might behave during a processing operation. Large scale tests that help in these assessments are: a machining over-test; and possibly Steven tests, Susan tests, Spigot tests, Bullet impact tests, Thermal decomposition tests, and of course the Skid-test. These large-scale tests generally use PBX 9404 as the basis for comparison.

The macro behavior of a consolidated part is heavily dependent on the composite nature of the material. The ideal explosives used in the DOE complex are of two types, pure and plastic bonded. Safety data for the pure HEs (TNT) tend to scale-up from small-scale properties relatively well. Plastic bonded materials cannot be addressed so easily. The binder plays a big role in how a part will behave when mistreated. Binders provide separation between HE crystals, they can dissipate or conduct heat, and they can make a part softer and less stiff. The type of binder and the proportions of binder and HE are critical to how a given explosive billet behaves.

The process of safe HE manufacturing is one that depends upon an involved safety process. Single piece engineered PBX components can be made weighing as little as a gram and as much as a few hundred kilograms. The success of HE manufacturing in the DOE, is derived from well-understood explosives, engineering controls, administrative controls, training, and formality of operations. Engineered processes and the use of safe materials have made the fabrication process somewhat routine. The engineered process are very mature and consistent, the problem arises when wanting to work with a new material. This drives home the need for a few safety tests of large explosive parts that can be relied upon for making safety judgments on a particular material or operation. The skid-test is one of those tests. It is important to the HE manufacturing sector because it provides an indication of how a consolidated charge might behave if accidentally dropped, released from a machine, 
it falls from a table, etc.. The intent of this paper is to develop a simple model to help study how binder changes the properties of HMX based PBXs in the skid-test. 


\section{BACKGROUND}

\section{THE SKID-TEST}

The skid-test was first conceived in the UK at AWRE in 1960 and has been used in the DOE Complex since 1961, as a means to measure sensitivity for large charges in handling situations. While no single test can capture an explosive's behavior for all types of stimuli, the skid-test is a nice indicator of how a large hemispherical billet will behave when dropped at some angle of incidence onto a rigid surface. Usually, the steel boilerplate has an abrasive surface in the form of sand paper or grit bonded to the plate. There are two types of skidtests in use today: The Los Alamos test engages the free fall (usually guided on a cable) of a 20 pound (ten inch diameter) solid billet onto an eight inch boiler plate elevated at $45^{\circ}$, Figure 1\&2. The target is covered with 80 grit sandpaper glued onto a $1 / 4$ inch thick aluminum plate. High-speed movies and blast overpressure gauges are used to analyze the outcome. Variables in the skid-tests are drop height, angle of impact, and surface condition on the target. The Pantex test hoists the 25 pound (11 inch diameter) charge in a harness, on a pendulum, allowing the charge to strike a horizontal surface at a range of angles (either $14^{\circ}$ or $45^{\circ}$ ), Figure 3. The target plate is bonded to the concrete pad and is covered with Silver coated sand/epoxy bonded to 0.25 in. thick steel plate. 
Figure 1 Wire Guided Free-Fall Skid Test
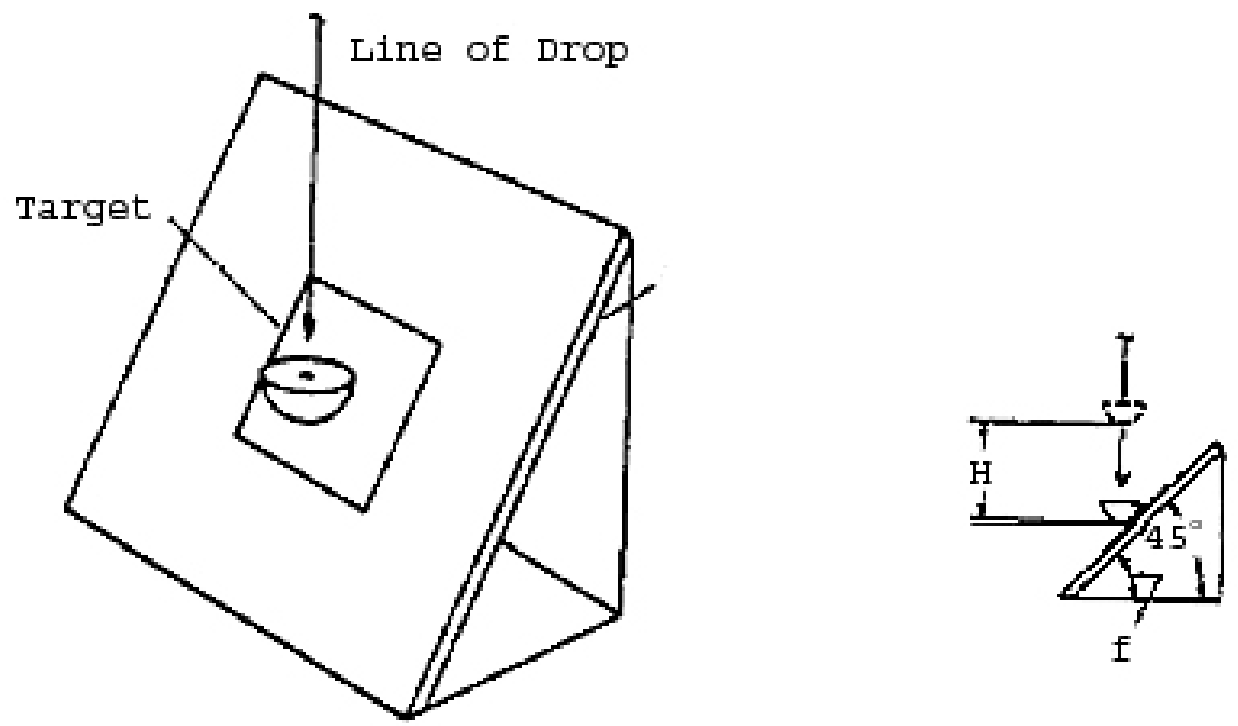

Figure 2 LANL Skid Test Summary

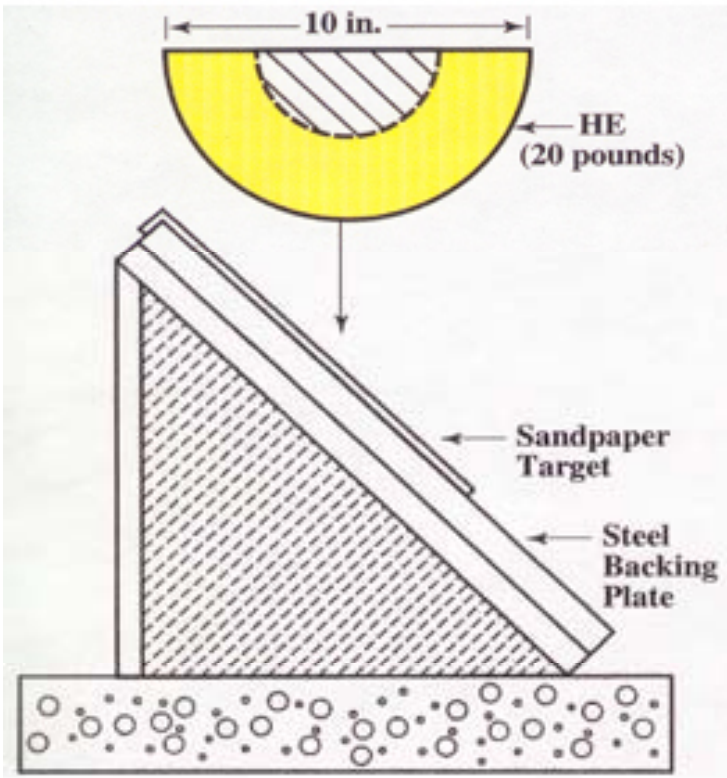

\begin{tabular}{|l|c|c|}
\hline \multicolumn{1}{|c|}{ Explosive } & H50 $_{50}$ ft.) & $\begin{array}{c}\text { Overpressure } \\
\text { (psi) at 10 ft. }\end{array}$ \\
\hline 1. PBX 9404 & 4.5 & $15-20$ \\
\hline 2. LX-10 & 3 & 25 \\
\hline 3. PBX 9501 & 26 & 1 \\
\hline 4. PBX 9502 & $>150$ & No Rxs \\
\hline 5. PBX 9010 & 2.5 & 13 \\
\hline 6. PBX 9011 & 78 & 1 \\
\hline
\end{tabular}




\section{Figure 3 Pendulum Skid Test Configuration}

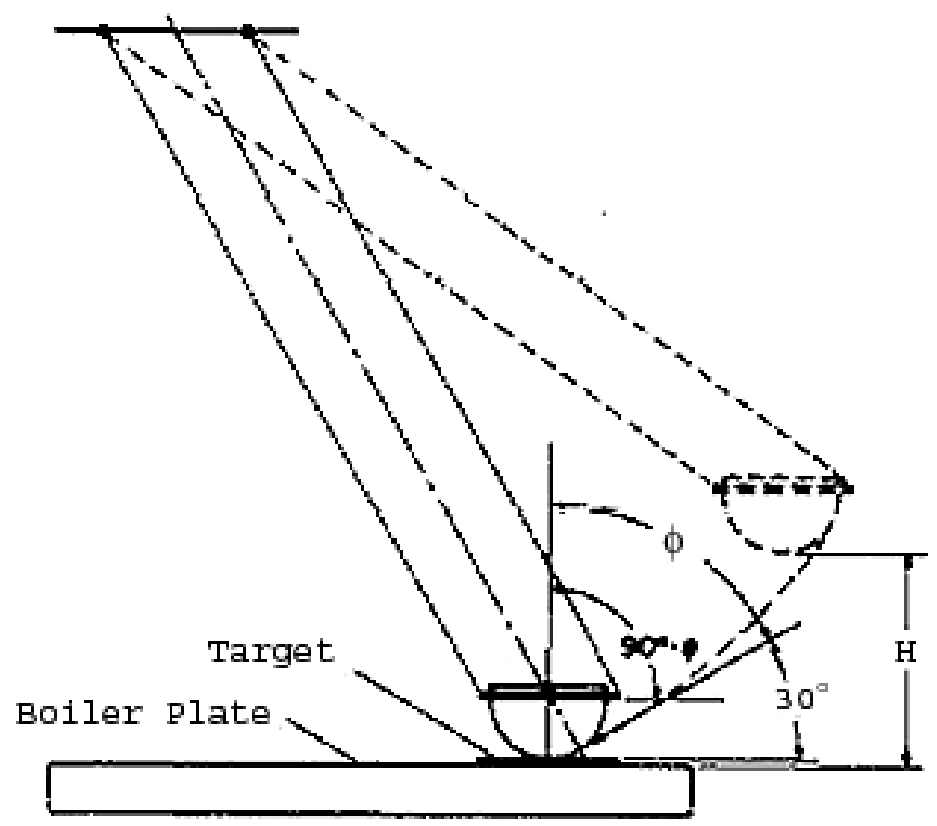

\section{SKID TEST STATISTICS}

Results of the skid-test are go \& no-go scoring and a characterization of the type of chemical event produced. The chemical event scoring used in the Pantex test are:

0 No reaction. Charge retains integrity.

1 Burn or scorch marks on HE or target. Charge retains integrity.

2 Puff of smoke, but no flame or light visible in high speed photography. Charge may retain integrity or may be broken into large pieces.

3 Mild low-order reaction with flame or light. Charge broken-up and scattered.

4 Medium low-order reaction with flame or light. Major part of $\mathrm{HE}$ consumed.

5 Violent deflagration. Virtually all HE consumed.

6 Detonation.

The statistics of scoring the 50\% drop height in the skid-test are approached using the Bruceton or Up - Down method ${ }^{(1)}$. This method works well when it is easy to adjust the 
independent variable (drop height in this case) and assumes a normal distribution for the data. The technique is good for estimating the mean (50\% drop height) but is less reliable for the standard deviation. Prior to starting the test, one makes a best guess at a 50\% drop height $y$ ' and an increment to adjust each subsequent shot, $d$. For best results, $d$ of about $0.5 \sigma$ should be used. The first sample is dropped from y' and either a go $(G)$ or no-go $(N)$ is recorded. If it is a go, the next sample is dropped from y'-d and the result recorded. If the first drop were a no-go, then the next sample is dropped from $y$ ' $+d$. Subsequent samples are dropped from a height of $+d$ if they are a no-go and $-d$ if they are a go. An odd number of tests are used since the scoring of the results involves using only the event occurring less frequently. As an example, consider a material where the initial height is chosen to be $7 \mathrm{~m}$ and the increment is chosen as $1 \mathrm{~m}$. The results from the drops are:

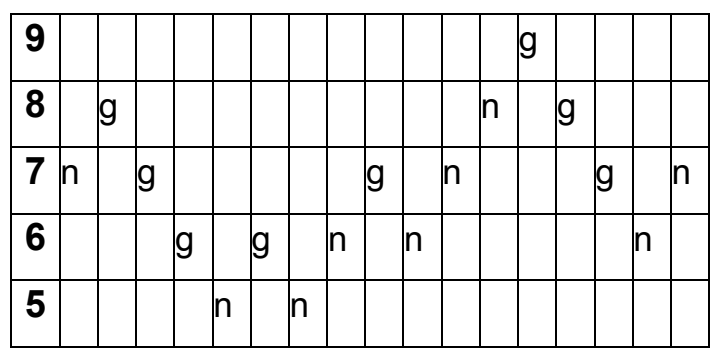

In this case, there are eight go and nine no-go, so the data from the no-go's will be used in calculating drop height. The lowest level where there is a no-go is $5 \mathrm{~m}$, and this is called $\mathrm{y}_{0}$. The data would be tabulated as follows:

\begin{tabular}{|c|c|c|c|c|}
\hline Height & i & $n_{i}$ & $\mathbf{i}^{*} \mathbf{n}_{\mathbf{i}}$ & $i^{2 *} n_{i}$ \\
\hline 8 & 3 & 1 & 3 & 9 \\
\hline 7 & 2 & 3 & 6 & 12 \\
\hline 6 & 1 & 3 & 3 & 3 \\
\hline 5 & 0 & 2 & 0 & 0 \\
\hline & & $\mathrm{N}=9$ & $A=12$ & $B=24$ \\
\hline
\end{tabular}


The $50 \%$ drop height would be calculated by $\bar{y}=y_{0}+d\left(\frac{A}{N} \pm \frac{1}{2}\right)$ where the + is used if the symbols at the smallest value ( $\mathrm{n}$ in this case) is used, and - is used if the symbol at the largest value is used ( $\mathrm{g}$ in this case). In this case the $\mathrm{n}$ is being used, so the plus sign is used. The $50 \%$ drop height for this example is $\bar{y}=5+1\left(\frac{12}{9}+\frac{1}{2}\right)=6.83 \mathrm{~m}$. The standard deviation is calculated according to the formula $\sigma=1.620 d\left(\frac{N B-A^{2}}{N^{2}}+0.029\right)$. This formula is only valid if $\left(\frac{N B-A^{2}}{N^{2}}\right)<0.3$, which is not true for this example. The point of this explanation is that reporting of skid-test results is very much statistical and not an exact science. Experience has shown that nominally identical billets can provide go's at one level and a nogo at a level or two higher in height. There are some theories on why this might be, revolving around statistical number and size of voids near the impact point. Localized inhomogeneities are a leading explanation on why the skid-test must be addressed statistically.

Even so, bare (unconfined) billets of HMX based plastic bonded explosives are generally pretty well behaved in a normal impact on smooth surfaces. Randolph, Hatler, and Popolato $^{(2)}$ illustrate the difference between impact on a smooth target and impact on a rough oblique target that induces sliding or skidding. In the former, PBX 9404 impact velocities of about $30 \mathrm{~m} / \mathrm{s}$ are required to initiate a reaction (violent deflagration or detonation) whereas in the later, impact velocities of about $3 \mathrm{~m} / \mathrm{s}$ result in initiation. There are two underlying questions that need to be answered. How is the mechanical energy of the impact or friction able to initiate a chemical reaction leading to initiation? And, why does grit so dramatically increase the sensitivity of the $\mathrm{HE}$ in a low velocity impact? 


\section{LITERATURE REVIEW}

\section{THERMAL EXPLOSION THEORY}

Bowden and Yoffe ${ }^{(3)}$, make a convincing argument, through experiment, that initiations of this type are thermal in nature. They investigate the physical processes involved in initiation of explosive substances by impact or friction. They consider both solid and liquid explosives and conclude that mechanical energy can be converted into heat in a very localized region, thus forming a hot-spot. They address formation of hot-spots through three thermomechanical mechanisms: 1) Adiabatic compression of voids that exist between the crystalline explosive; 2) Friction between HE crystals, extraneous grit particles, or confining surfaces; and 3) Viscous heating of the rapidly flowing explosive as it escapes between impacting surfaces. They conclude that void compression hot-spots coupled with grit induced heating is the likely mechanism for initiation of secondary HE's. Primary HE's are more likely initiated by crystalline friction since they usually detonate below the melting point of the grit particles. These results are consistent with the fact that under slow heating, primary explosives decompose violently prior to melting while secondary explosives melt prior to decomposition. While data supports these theories, they caution that understanding the mechanism of initiation for a given explosive under specific impact conditions is important. "These general observations are of some practical interest, since they may help to explain the erratic but sometimes disastrous explosions which occur from time to time. ... If, for example, initiation is due to a hot spot on the confining surfaces the probability of an explosion can be diminished by making the surfaces of a low-melting alloy. If it is due to friction between particles coating the particles with a lubricating wax might diminish it. Neither of the methods would be effective, however, if the initiation were in reality due to an included bubble." It is this state of uncertainty that led Randolph, Hatler, and Popolato ${ }^{(2)}$ to explore rapid heating in the skid-test and mechanisms specific to the skid-test will be discussed in a later section.

Bowden and Yoffe ${ }^{(3)}$ go on to explore the influence of grit in sensitizing an explosive. They demonstrate that grit particles aid in the creation of hot spots and the grit properties of 
importance are melting temperature, size, hardness, and thermal conductivity. A series of experiments by Bowden and Gurton ${ }^{(4)}$ showed that the temperature rise (hot-spot) is limited by the melting point of the grit. They found with PETN, that grit particles with melting temperatures greater than $430{ }^{\circ} \mathrm{C}$ are effective in causing explosion, while grits less than $400{ }^{\circ} \mathrm{C}$ are ineffective. Hot spots are a transient event that must exist for long enough to allow for a finite quantity of the HE to decompose. Time scale of these hot spots is $10^{-3}$ to $10^{-5} \mathrm{sec}$, and hot spot sizes range from $10^{-3}$ to $10^{-5} \mathrm{~cm}$. Initiation by thermal decomposition then becomes a competition between heat generated in the exothermic reaction and heat dissipated through conduction, convection, and radiation in or around the reaction zone.

\section{THERMAL DECOMPOSITION THEORY}

We know that all explosives that are above absolute zero are thermally decomposing. It is generally accepted that most explosives, at normal operating temperatures, decompose according to a zero order reaction rate law, i.e. the rate depends only upon the temperature. The rate of heat production through decomposition can be defined by:

$$
q=\rho Q Z e^{-E_{a} / R T}
$$

where $q$ is the rate of heat evolved per unit volume; $\rho$ is the density; and $Q$ is the heat of reaction. This heat is then transferred to the surrounding explosive through conduction, at a rate dependent upon thermal conductivity, heat capacity, and density. The FrankKamenetskii equation describes this thermal energy balance.

$$
\left(-\lambda \nabla^{2} T\right)+\rho C\left(\frac{d T}{d t}\right)=\rho Q Z e^{-E_{a} / R T}
$$

where $\lambda$ is the thermal conductivity and $C$ is the heat capacity. This second order partial differential equation is best solved numerically. To make this a more tractable problem, one can consider the steady state solution where time approaches infinity. While this is not a realistic assumption for the skid-test scenario, it does make available an engineering tool to estimate temperatures required to initiate the billets. To further simplify the calculation, geometry can be restricted to three idealized shapes, the infinite slab, the infinite cylinder, 
and the sphere. The Laplacian operator $\left(\nabla^{2}\right)$ then becomes dependent on a single linear dimension, shown as

$$
\nabla^{2} T=\delta^{2} T / \delta x^{2}+(r / x)(\delta T / \delta x)
$$

where $\mathrm{r}$ is the half thickness of the semi-infinite slab or radius of the sphere or cylinder. Equations 2 and 3 can be combined and solved at steady state for the three geometries to obtain the following expression ${ }^{(5)}$

$$
\frac{E_{a}}{T_{c}}=R \ln \left(\frac{r^{2} \rho Q Z E_{a}}{T_{c}^{2} \lambda \delta R}\right)
$$

where $E_{a}$ is the activation energy in cal/mole; $T_{c}$, the critical temperature in $K$; $R$, the universal gas constant $(1.9872 \mathrm{cal} /$ mole $\mathrm{K}) ; \rho$, is the charge density in $\mathrm{g} / \mathrm{cm}^{3} ; \lambda$, is the charge thermal conductivity in $\mathrm{cal} / \mathrm{cm} \sec \mathrm{K}$; Q, the heat of decomposition reaction in $\mathrm{cal} / \mathrm{g}$; Z, the pre-exponential factor in $\mathrm{s}^{-1}$; and $\delta$, is the shape factor; 0.88 for a semi-infinite slab; 2.00 for an infinite length cylinder; 3.32 for a sphere. While this equation is very useful for determining steady state critical temperatures, the dynamic skid test event requires solving the transient FK equation (Eqn 2).

\section{Charles Mader's ANALYTIC SOlution}

Charles Mader ${ }^{(6)}$ developed an approach to solve the Frank-Kamenetskii equation, equation 2, numerically. Mader's approach was to develop a solution in a single spatial dimension plus a time dimension. He further split the problem into a conduction only segment followed by a reactive growth segment. The result is a solution for temperature as a function of time in a single spatial variable, $\mathrm{x}$. The scenario is, the one-dimensional HE slab of halfthickness $\mathrm{r}$ is initially at $\mathrm{T}=\mathrm{T}_{0}$; at time $\mathrm{t}=0$, the outer surfaces at $\mathrm{x}=0$ and $\mathrm{x}=2 \mathrm{r}$, are raised to $\mathrm{T}_{1}$. If one initially ignores the reaction heating term in equation $2, \rho Q Z e^{-E_{a} / R T}$, the equation becomes $\left(\lambda \nabla^{2} T\right)=\rho C\left(\frac{d T}{d t}\right)$. Utilizing the above boundary conditions and knowing the temperature as a function of $\mathrm{x}, \mathrm{T}=\mathrm{f}_{0}(\mathrm{x})$, the temperature as a function of $\mathrm{x}$ and $\mathrm{t}$ becomes 


$$
T(x, t)=T_{1}+\frac{1}{r} \sum_{n=1}^{\infty} e^{-\left(\frac{n^{2} \pi^{2} \lambda t}{4 \rho C r^{2}}\right)} \sin \left(\frac{n \pi x}{2 r}\right) \int_{0}^{2 r}\left[f_{0}(x)-T_{1}\right] \sin \left(\frac{n \pi x}{2 r}\right) d x
$$

This equation defines how the temperature changes with time and position as a result of conduction. If $\mathrm{f}_{0}(\mathrm{x})$ is known at enough points, the integral can be solved analytically. Mader proposed solving this problem computationally by dividing time into small increments, $\tau$. Initially the slab's faces at $x=0$ and $x=2 r$ are at a uniform low temperature $T_{0}$. At time $\mathrm{t}=0$, the two faces are raised to the temperature $\mathrm{T}_{1}$. One initially assumes that there is no reaction heat generated (the slab is inert) and obtains an approximation to the temperature at $\mathrm{t}=\tau_{1}$, as a function of $\mathrm{x}$ using equation 6 where $\mathrm{f}_{0}(\mathrm{x})$ is initially constant at $\mathrm{T}_{0}$. With $\mathrm{T}\left(\mathrm{x}, \tau_{1}\right)$ due to conduction known, the temperature change resulting from the chemical reaction is then joined with this first estimate of temperature. In equation form, $\mathrm{T}\left(\mathrm{x}, \tau_{1}\right)$ is revised to

$\mathrm{T}\left(\mathrm{x}, \tau_{1}\right)+\left(\left(Q Z \tau_{1}\right) / C\right) e^{-E_{a} / R T\left(x, \tau_{1}\right)}$

During the next interval, $\tau_{2}$, the slab is again treated as inert to calculate a conduction only temperature using equation 6 . This time, $\mathrm{f}_{0}(\mathrm{x})$ is not constant, and is set equal to

$\mathrm{T}\left(\mathrm{x}, \tau_{1}\right)+\left(\left(Q Z \tau_{1}\right) / C\right) e^{-E_{a} / R T\left(x, \tau_{1}\right)}$. This piecewise process is continued until the temperature runs away at a certain positional location.

\section{INITIATION OF EXPLOSION IN SOLIDS BY IMPACT}

The overall thermal energy created by the impact of a hemispherical billet on a target is relatively small. In fact, there is only enough conversion of mechanical energy to thermal energy to raise the entire billet temperature by a few degrees. It is the concentration of this thermal energy over a relatively small area $(\sim 1$ inch in diameter) that is responsible for the initiation. Beedham, Dyer, and Holmes, 1970 (7) set out to study this effect by dropping charges onto an electrically heated hot plate. They confirmed what was suggested by Bowden and Yoffe, that is, secondary explosives must see hot spot temperatures of $>430^{\circ} \mathrm{C}$. 
Beedham, Dyer, and Holmes report that HMX and RDX compositions give explosive reactions in the range of $400-470{ }^{\circ} \mathrm{C}$. These temperatures are well above what is reported as the thermal initiation temperatures $\left(215-260{ }^{\circ} \mathrm{C}\right)$.

There are three primary constituents in a reacting PBX material, the explosive, the binder, and the reactant gases. The pressure (normal stress) serves to provide confinement for both the heat loss and reacting gases. The dynamics of the event must be such that the build up of heat occurs during the short time the billet is inertially stuck to the target. Confinement can be of even greater importance to a detonation that develops through the rapid decomposition of the reaction products. Beedham, Dyer, and Holmes also note that at the impact temperatures achieved, there is a thin molten layer of explosive and the pressure is important to maintain good thermal connectivity with the hot target. They conclude that this is not a significant effect, except with TNT materials, where the melt can escape the confinement.

Dyer and Taylor, $1970{ }^{\left({ }^{(8)}\right.}$ also studied the frictional mechanisms that lead to detonation. They noted that a billet dropped vertically on a target required an order of magnitude increase in height over the same billet dropped in the oblique skid-test. They showed that water on a target was enough lubricant to forestall a detonation in the skid-test where otherwise there would have been a detonation. They also coin the term "explosiveness" as something to be considered in addition to sensitivity. From explosive to explosive, there are widely varying reactions from a puff of gas to full-scale detonation. They studied the effect of grit and conclude that it is grit-to-grit interactions that causes detonations. Their theory suggests that the gases of a neighboring particle aid the gases created around a single grit particle. The micro-regions around these two particles hinder the escape of gas and allow the creation of the higher pressures.

\section{INITIATION BY FRICTION IN THE SKID-TEST}

Randolph, Hatler, and Popolato ${ }^{(2)}$ developed a model to predict drop height based upon the heat generated due to friction of the charge at impact. Their model uses Fourier's Law to partition the thermal flux from impact into conduction in the target and conduction in the charge. This model assumes that all the energy of impact is converted to heat and neglects viscous dissipation in the charge. The importance of target conduction was studied using 
three different target materials. An Arrhenius reaction rate law was used for the charge decomposition as a function of temperature. They used a zero-order law, which ignores the fraction of $\mathrm{HE}$ reacted. With a model at hand, they ran experiments to verify results and benchmark the model.

Development of their friction thermal initiation model begins with calculating heat flux generated at the billet-target interface

$q=\mu \sigma V_{T} / J$

where $\mu$ is the apparent coefficient of friction equal to the ratio of tangential to normal contact forces; $\sigma$ is the normal contact pressure (plastic flow stress if there is assumed to be no rebound); $V_{T}$ is the sliding velocity, and $\mathrm{J}$ is the conversion factor from mechanical to thermal units. Figure 4 shows a schematic of the impact and defines the variables of the impact. 
Figure 4 Billet Dynamics, Just Before \& at Impact

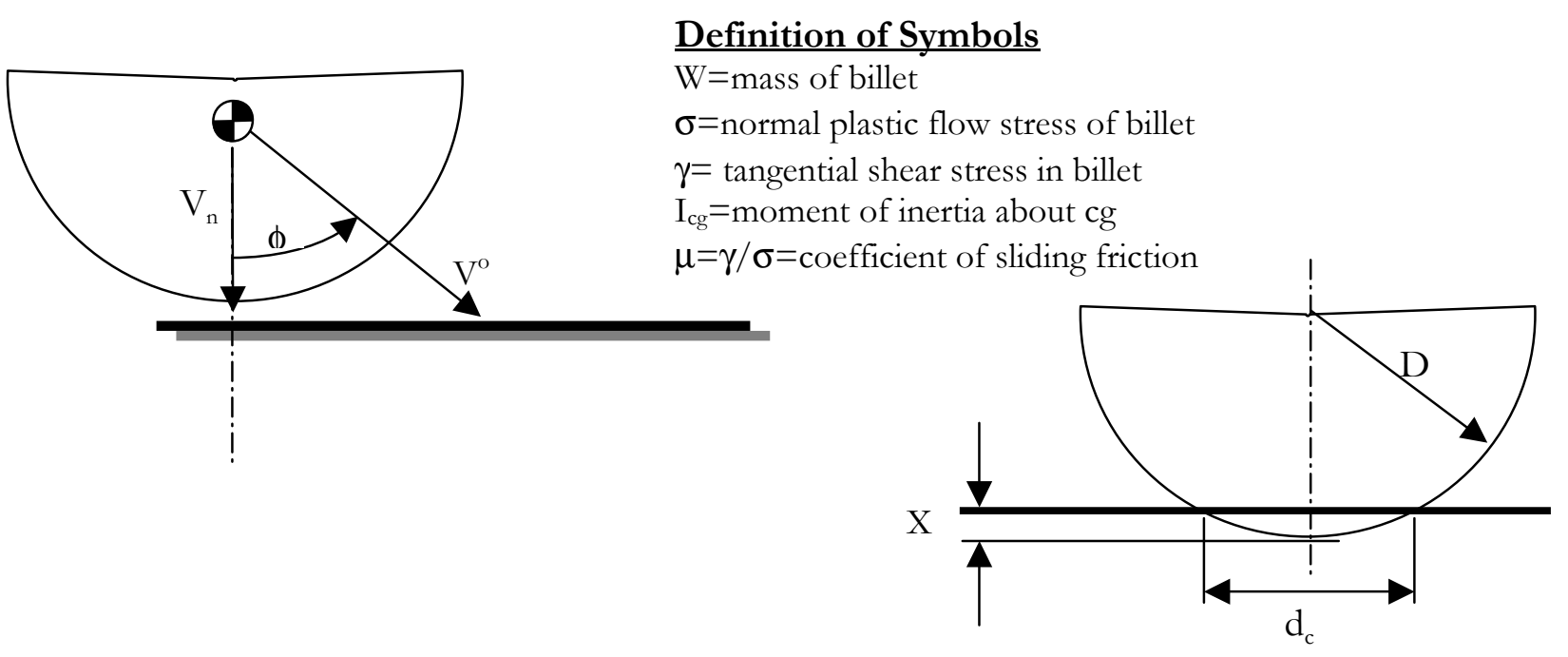

Using the equations of motion, the geometry of the skid-test, and some initial conditions, Hatler et. al. go on to derive dynamic equations for the oblique impact of a plastic bonded hemispherical billet on a rigid target. The relevant equations defining the impact follow in Table 1. 
Table 1

Dynamic Equations for Oblique Impact of PBX Hemisphere on Rigid Target

\begin{tabular}{|c|c|c|}
\hline Contact Time & $t_{c}=(\pi / 2)\left(\begin{array}{lll}W & / \pi \sigma & D\end{array}\right)^{1 / 2}$ & (8) \\
\hline $\begin{array}{l}\text { Normal } \\
\text { deformation }\end{array}$ & $\begin{array}{l}X=\left(V_{n}^{0} / \omega\right) \sin \omega t \\
\text { where } \omega=(\pi \sigma D / W)^{1 / 2} \text { and } V_{n}^{0}=V^{0} \cos \Phi\end{array}$ & $\begin{array}{l}\text { (9) } \\
(9 \mathrm{a}) \& \\
(9 \mathrm{~b})\end{array}$ \\
\hline $\begin{array}{l}\text { Normal } \\
\text { Velocity }\end{array}$ & $\begin{array}{l}V_{n}=V_{n}^{0} \cos \omega t \\
\text { where } \mathrm{V}_{\mathrm{n}}^{0} \text { is velocity normal to target at instant of impact }\end{array}$ & (10) \\
\hline $\begin{array}{l}\text { Maximum } \\
\text { Contact Area }\end{array}$ & $A_{c}=\pi D V_{n}^{0} / \omega$ & (11) \\
\hline $\begin{array}{l}\text { Rotational } \\
\text { Velocity }\end{array}$ & $\begin{array}{l}\Theta=\left[\left(a^{\prime} \mu+b^{\prime}\right) D V_{n}^{0} W / 2 I_{c g}\right](1-\cos \omega t) \\
\text { where } \mu=\gamma / \sigma \text { and } \mathrm{a}^{\prime}=1-0.375 \cos \Phi \text { and } \mathrm{b}^{\prime}=0.375 \sin \Phi\end{array}$ & (12) \\
\hline $\begin{array}{l}\text { Terminal } \\
\text { rotational } \\
\text { velocity }\end{array}$ & $\Theta_{c}=\left[\left(a^{\prime} \mu+b^{\prime}\right) D V_{n}^{0} W / 2 I_{c g}\right]$ & (13) \\
\hline $\begin{array}{l}\text { Tangential } \\
\text { Velocity }\end{array}$ & $\dot{Y}_{c g}=\left(V_{T}\right)_{c g}=V^{0}[\sin \Phi+\mu \cos \Phi(\cos \omega t-1)]$ & (14) \\
\hline $\begin{array}{l}\text { Sliding } \\
\text { Velocity }\end{array}$ & $\begin{array}{l}V_{T}=V^{0} \sin \Phi-V^{0}\left[\mu+\left(a^{\prime} \mu+b^{\prime}\right)\left(D W X_{3}\right) /\left(2 I_{c g}\right)\right] \cos \Phi(1-\cos \omega t) \\
\text { where } X_{3}=(D / 2)\left[\left(a^{\prime}\right)^{2}+\left(b^{\prime}\right)^{2}\right]^{1 / 2}\end{array}$ & (15) \\
\hline
\end{tabular}

Since the initial drop velocity, $\mathrm{V}_{0}$, is typically zero, the final velocity, $\mathrm{V}^{0}$, is proportional to the square root of the drop height by the following relationship

$V^{0}=\sqrt{2 g H}$

By combining equations $16 \& 11 \& 9 \mathrm{~b}$, the maximum contact area as a function of drop height can be established 


$$
A_{c}=\frac{\pi D(2 g H)^{1 / 2} \cos \Phi}{(\pi \sigma D / W)^{1 / 2}}
$$

It can be quickly seen then, that the contact area is also proportional to the square root of drop height. By solving for $\mathrm{d}_{c}$, the maximum spot diameter, it can be found that it is proportional to the drop height to the $1 / 4$ power

$$
d_{c}=\frac{2(2 D g H)^{1 / 4}(\cos \Phi)^{1 / 2}}{(\pi \sigma / W)^{1 / 4}}
$$

Spot diameter then becomes a function of charge geometry and weight, plastic flow stress, and impact angle. If the thermal ignition postulation is accurate, and thermal losses are only by conductivity partitioned between target and billet, then one can argue that plastic flow stress is a key parameter in skid-test sensitivity. The softer a material, or lower plastic flow stress, the larger the spot diameter will be at impact. Larger spot diameter translates into more heat conduction and therefore a safer condition. Figure 5 shows data that supports this theory. Note the log-log linear behavior of 50\% drop height to dynamic material strength for several HMX based PBX composite materials. The compositions of these materials are contained in Table 2 later in this paper. 
Figure 5 Skid Test Sensitivity vs Mat'l Strength for HMX based Mat'ls

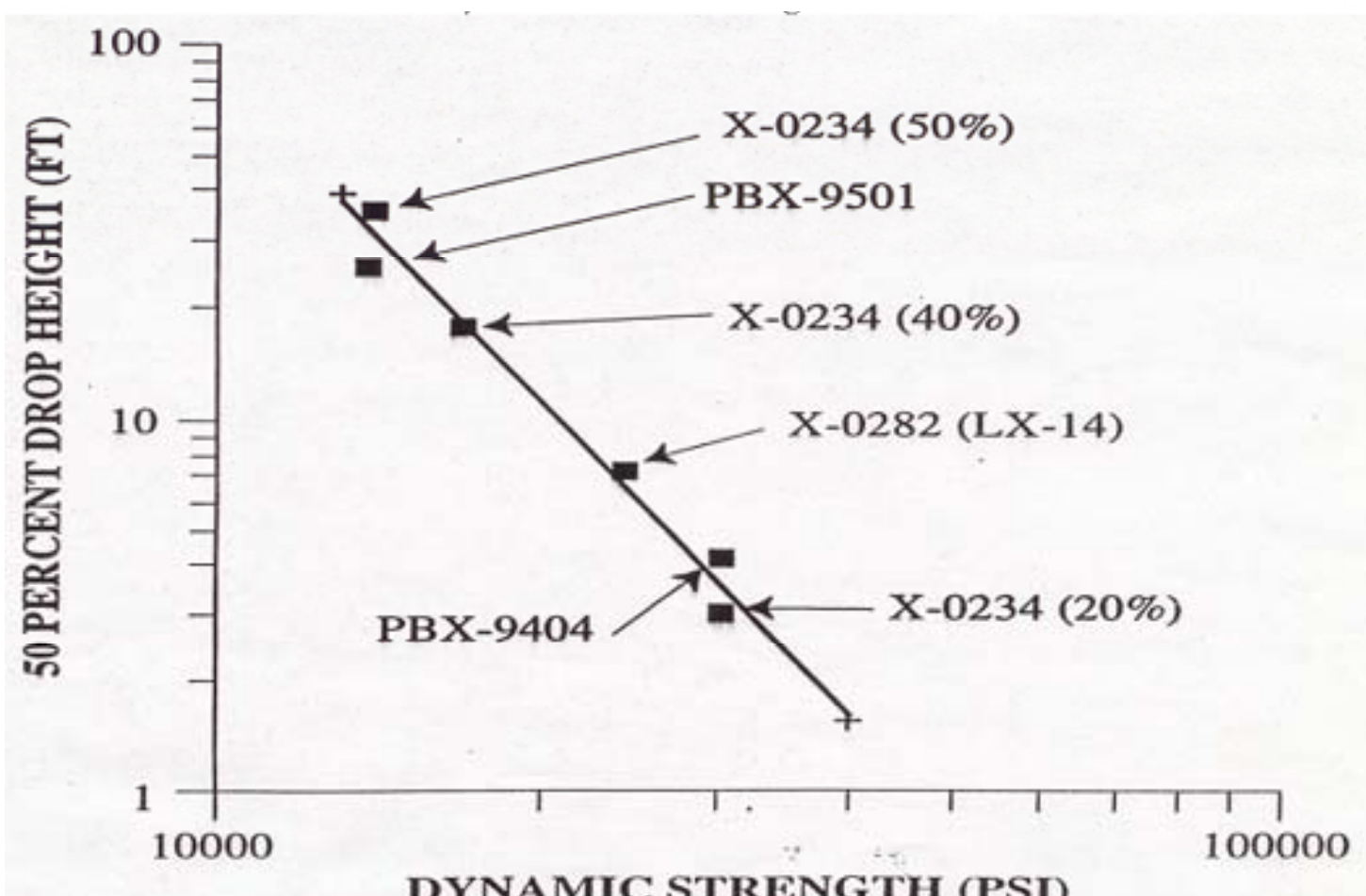

\section{CHARLES ANDERSON'S SKID TEST MODEL}

Charles Anderson ${ }^{(9)}$ set out to calculate 50\% skid-test drop heights in 1962 with the belief that the coupling of dynamic mechanical properties to the chemical kinetics can allow one to make the predictions. It should be no surprise that the dynamic equations of rigid body motion were identical to those of Hatler et. al. in Table 1. Anderson goes on to derive an expression for surface temperature as a function of time resulting from the frictional dissipation of mechanical energy. This derivation assumes constant flux over the duration of contact. Anderson derives the following expression for temperature as a function of time

$$
T_{s}(t)=\frac{2 \delta \mu \sigma V_{s}^{0}}{\lambda} \sqrt{\alpha t / \pi}
$$


where $\mu$ is the coefficient of friction of the explosive on the target, $\sigma$ is the dynamic $(\sim 100$ $\mathrm{sec}^{-1}$ ) ultimate strength of the explosive, $\lambda$ is the thermal conductivity of the explosive, and $\alpha$ is the thermal diffusivity. $\delta$ is a constant that accounts for the apparent and actual contact area differences due to surface roughness and the partitioning of some of the heat into the target. For the calculations Anderson discussed, he used a value of 0.2 for $\delta . V_{s}^{0}$ is the initial velocity tangent to the surface of the target and is defined as

$V_{s}^{0}=V_{0} \sin \Phi$

Combining equations 16, 19, and 20, one arrives at an expression for temperature as a function of time for a given drop height

$$
T_{S}(t)=\frac{2 \delta \mu \sigma(\sqrt{2 g H} \sin \Phi)}{\lambda} \sqrt{\alpha t / \pi}
$$

The contact time from equation 21 is defined by equation 8 . Combining equations 8 and 21 results in the following expression for temperature

$$
T_{s}(t)=\frac{2 \delta \mu \sigma(\sqrt{2 g H} \sin \Phi)}{\lambda} \sqrt{\alpha(\pi / 2)(W / \pi \sigma D)^{1 / 2} / \pi}
$$

Equation 22 will be used later to calculate the temperatures achieved at the surface of the charge as a result of converting mechanical energy to thermal energy. It is worth noting here that the temperatures achieved are strictly a function of charge size, material properties, drop height and dynamic strength of the billet. This equation demonstrates that under the same handling accident conditions, stronger billets result in higher surface temperatures at impact. There is also a linear correlation between temperature and dynamic strength. So, if a billet is made $25 \%$ stronger by changing the binder, there is going to be roughly a $25 \%$ increase in temperatures achieved at the surface. The problem is, there is no simple formula for what localized surface temperature is required to achieve detonation. We know from the work of Bowden and Yoffe, that hot-spots of $\sim 430{ }^{\circ} \mathrm{C}$ are required for detonation in secondary explosives. One can also use this temperature as an input to the one-D reactive heat conduction equations, equations 5 and 6 above. 


\section{A COMPREHENSIVE SKID-TEST COMPUTER CODE}

A comprehensive model and FORTRAN code, SKID1, was developed by Younger and

McIlraith, $1967^{(10)}$. The code is versatile and allows the user to input a wide variety of material properties supporting an analysis that is elastic, perfectly plastic, or a combination of the two. The code also allows several different drag and frictional behaviors to be modeled. Target properties are also variable from rigid to flexible, with different materials and grit conditions. Reaction is modeled by a first order Arrhenius equation. While the model is far more sophisticated than what is being proposed here, it seems to agree with the supposition that charge compliance (dependent upon binder) is an important property in how a sensitive a billet is in the oblique impact test.

Some of their conclusions are:

1) For the same drop height, a $14^{0}$ impact will result in a significantly higher friction temperature than a $45^{\circ}$ impact. This of course is due to the much higher $\mathrm{V}_{\mathrm{T}}$.

2) For the same initial impact angle the friction temperature rise will increase with drop height.

3) The duration of the contact period does not vary with drop height for constant flow stress assumption. This observation is consistent with the impact time derivation above, equation 6. Contact duration decreases with drop height for Hertz contact (elastic).

4) Large billets are more skid sensitive than small billets. This is due to the fact that the geometries are similar yet the impact is concentrated over similar areas. Dissipative effects are still confined to the spot diameter, which does not grow linearly with the increase in mass and therefore thermal flux.

5) As stated in this work, a higher thermal conductivity target would create a less skid sensitive test than a low conductivity target.

6) A rigid target is preferable to a soft target when trying to minimize skid sensitivity. 


\section{CALCULATIONS}

\section{FRANK-KAMENETSKII SEMI-INFINITE SLAB CALCULATION}

The Frank-Kamenetskii equation (eqn 2) is a reactive thermal conduction solution that assumes a temperature gradient between the surface of the charge and its interior. The FK equation can be simplified for one-dimensional geometry and the heat sectioned between conduction and chemical reaction, equations $6 \& 7$. The piecewise approach proposed by Mader will be used to approximate temperature as a function of time and location in a onedimensional semi-infinite slab. To adapt this solution to the skid-test, one must know what the surface temperature is raised to when the billets skids upon the target. Equation 22 is used to establish temperature. Equation 8 is used to establish how long this surface temperature is maintained. When a charge is dropped, testing has shown that a flat-spot develops on the surface of the charge at impact. This flat spot is a function of the drop height (final charge velocity) and the dynamic strength of the explosive material. For 9495\% HMX based plastic bonded explosives, tests have shown, and equation 18 has verified, the spot size to range from about 0.75 to 1.5 inch in diameter. If one considers the region about the flat spot as a semi-infinite slab, an FK calculation can be performed. Figure 6 is a schematic of skid-test approximations used to perform an FK calculation. 
Figure 6 Frank-Kamenetskii Semi-Infinite Slab Calculation

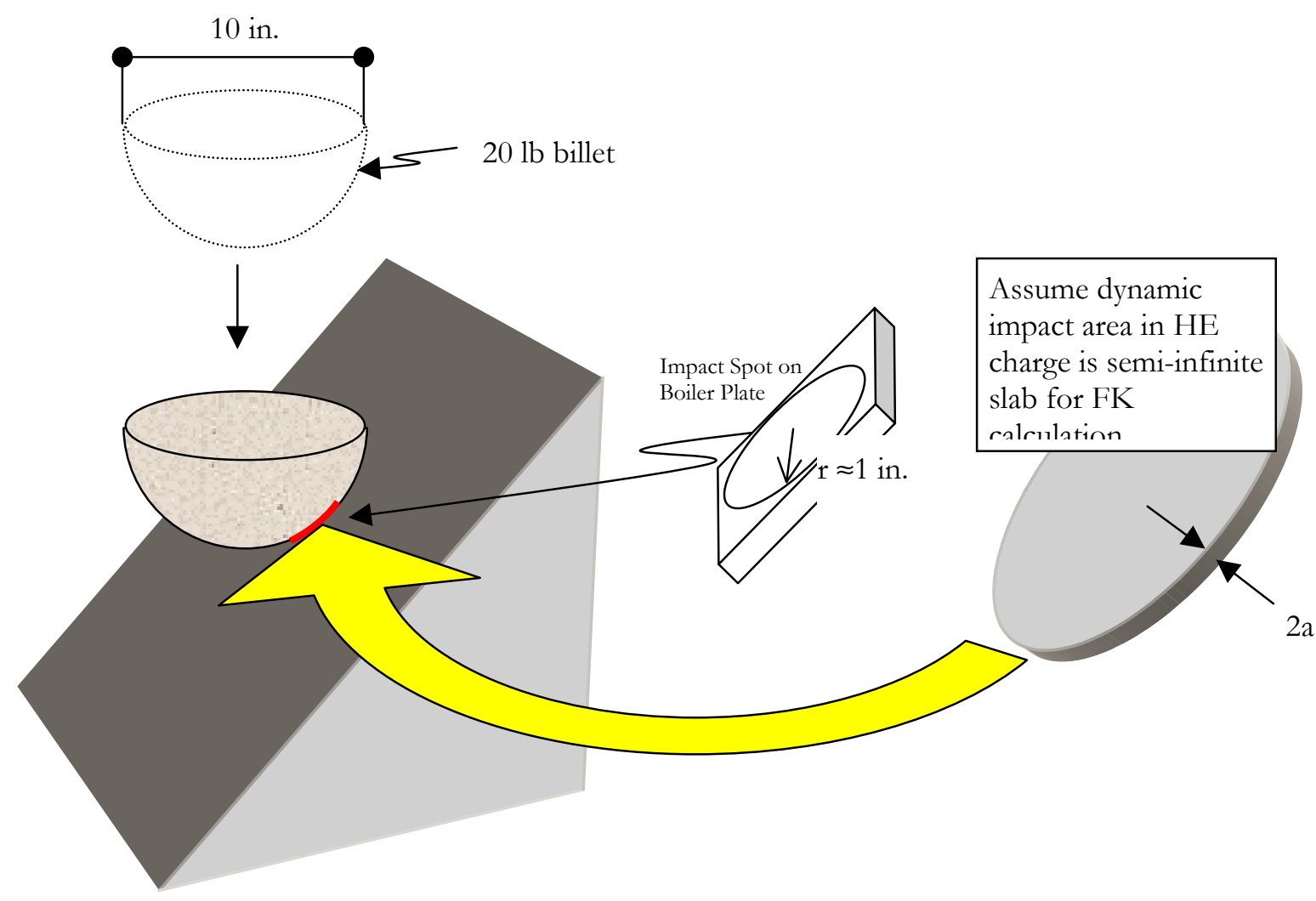

The model begins by using the Charles Mader ${ }^{(5)}$ analytical technique described earlier in this paper. With a body at uniform initial temperature $\mathrm{T}_{0}$, the surface is instantaneously raised to a higher temperature $T_{1}$. One proceeds forward by dividing time into small increments and assumes that there is no reaction heat initially generated over the time step. The temperature change by conduction is calculated as function of $\mathrm{x}$ for the time step using equation 6 . For the first time step, using the initial and boundary conditions identified above, equation 6 can be integrated as follows

$$
T\left(x, \tau_{1}\right)=T_{1}+\frac{1}{r} \sum_{n=1}^{\infty} e^{-\left(\frac{\mathrm{n}^{2} \pi^{2} \lambda \tau_{1}}{4 \rho C r^{2}}\right)} \sin \left(\frac{n \pi x}{2 r}\right)\left(T_{0}-T_{1}\right)\left(\frac{-2 r}{n \pi}\right)(\cos (n \pi)-1)
$$

One can plug this newly calculated spatial temperature distribution into the first order reaction equation and calculate a total temperature change as a function of position 
$\mathrm{T}\left(\mathrm{x}, \tau_{1}\right)+\left(\left(Q Z \tau_{1}\right) / C\right) e^{-E_{a} / R T\left(x, \tau_{1}\right)}$

This piecewise process is continued to until the temperature runs away at a certain positional location.

\section{BOUNDARY CONDITIONS}

The analytical problem needs to be bounded in terms of how much heat is introduced to the billet and for how long. Assuming an inelastic collision with no rebound, the billet will be in contact with the target for the duration determined by equation 8 . For the purposes of the calculations, it will be assumed that if a detonation is to occur, it will transpire within that time. The primary rationale for this assumption is that the pressure of contact contains the gases of reaction during this period. The elevated surface temperature, $\mathrm{T}_{1}$, is derived from equation 22, and is defined by several material/physical constants and the drop height. Several calculations were performed for each material, by increasing $\mathrm{H}$ to the point where a reaction ran away during the period defined by equation 8 . The calculations generally were sensitive enough that there was a clear point of runaway for drop heights within $0.1-0.2 \mathrm{~m}$.

\section{Material Property Data}

Key to an accurate model are the mechanical, thermal, and kinetics data for materials of interest. Data are challenging to find and have been assimilated from several sources and in some cases were assumed. Kinetics data for PBX materials is particularly difficult to come across and in some cases the HMX values were used for the PBXs. The single most critical piece of data is the dynamic strength at the appropriate strain rate. Again, data in the literature was scarce, so some assumption and extrapolation was used. The materials property data for the six HMX based materials chosen, are in Table 2. The data from Table 2 are collected from references 11, 12, 13. If a model like this were to be used in the early development of a new explosive, it would require some material property data, which is sometimes difficult to obtain. 
Table 2 - HMX Based PBX Material Properties

\begin{tabular}{|c|c|c|c|c|c|c|}
\hline & PBX 9501 & PBX 9404 & LX-14 & PBX 9011 & $\begin{array}{l}\text { X0234- } \\
94-20 \%\end{array}$ & $\begin{array}{c}\text { X0234- 94- } \\
50 \%\end{array}$ \\
\hline Composition & $\begin{array}{c}\text { HMX 95\% } \\
\text { Estane } 2.5 \% \\
\text { Bdnpa } 1.25 \% \\
\text { Bdnpf } 1.25 \%\end{array}$ & $\begin{array}{l}\text { HMX 94\% } \\
\text { NC 3\% } \\
\text { CEF 3\% }\end{array}$ & $\begin{array}{l}\text { HMX 95.5\% } \\
\text { Estane 4.5\% }\end{array}$ & $\begin{array}{l}\text { HMX } 90 \% \\
\text { Estane 10\% }\end{array}$ & $\begin{array}{c}\text { HMX } 94 \% \\
\text { DNPA } 4.8 \% \\
\text { CEF } 1.2 \%\end{array}$ & $\begin{array}{c}\text { HMX 94\% } \\
\text { DNPA 3\% } \\
\text { CEF 3\% }\end{array}$ \\
\hline $\begin{array}{l}\text { Activation } \\
\text { Energy } \\
\mathrm{E}_{\mathrm{a}}(\mathrm{cal} / \mathrm{mol})\end{array}$ & $4.01 \times 10^{4}$ & $3.13 \times 10^{4}$ & $4.01 \times 10^{4 d}$ & $5.27 \times 10^{4}$ & $3.13 \times 10^{4 d}$ & $3.13 \times 10^{4 d}$ \\
\hline $\begin{array}{l}\text { Density } \\
\quad \rho\left(\mathrm{g} / \mathrm{cm}^{3}\right)\end{array}$ & 1.835 & 1.873 & 1.840 & 1.770 & 1.840 & 1.847 \\
\hline 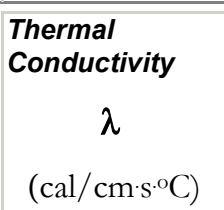 & $0.001084^{\mathrm{b}}$ & $0.00103^{\mathrm{a}}$ & $0.001049^{a}$ & $0.00103^{a}$ & $0.00103^{\mathrm{d}}$ & $0.00103^{\mathrm{d}}$ \\
\hline $\begin{array}{l}\text { Gas Constant } \\
\mathbf{R}(\mathrm{cal} / \mathrm{mol} \cdot \mathrm{K})\end{array}$ & 1.9872 & 1.9872 & 1.9872 & 1.9872 & 1.9872 & 1.9872 \\
\hline $\begin{array}{l}\text { Heat of } \\
\text { Decomposition } \\
\qquad \mathbf{Q}(\mathrm{cal} / \mathrm{g})\end{array}$ & 500 & 500 & 500 & 500 & 500 & 500 \\
\hline $\begin{array}{l}\text { Pre-exponential } \\
\text { Factor } \\
\qquad \mathrm{Z}\left(\mathrm{s}^{-1}\right)\end{array}$ & $5.90 \times 10^{14}$ & $4.30 \times 10^{12}$ & $5.90 \times 10^{14 d}$ & $5.00 \times 10^{19}$ & $4.30 \times 10^{12 \mathrm{~d}}$ & $4.30 \times 10^{12 \mathrm{~d}}$ \\
\hline $\begin{array}{l}\text { Heat Capacity } \\
\text { C }\left(\mathrm{cal} / \mathrm{g} \cdot{ }^{\circ} \mathrm{C}\right)\end{array}$ & $0.254^{\mathrm{a}}$ & $0.238^{\mathrm{a}}$ & $0.254^{\mathrm{d}}$ & $0.272^{\mathrm{a}}$ & $0.238^{\mathrm{d}}$ & $0.238^{\mathrm{d}}$ \\
\hline $\begin{array}{l}\begin{array}{l}\text { Ult. dynamic } \\
\text { strength }\end{array} \\
\quad \sigma(\mathrm{MPa})\end{array}$ & 24.1 & 49.3 & 36.2 & 34.2 & 55.1 & 15.3 \\
\hline $\begin{array}{l}\text { Thermal } \\
\text { Diffusivity }^{c} \\
\quad \alpha\left(\mathrm{cm}^{2} / \mathrm{s}\right)\end{array}$ & 0.00233 & 0.00231 & 0.00225 & 0.00214 & 0.00235 & 0.00234 \\
\hline $\mathrm{a}-$ Temp. $=$ & C & b-Temp. & $55^{\circ} \mathrm{C}$ & - Calculate & $y$ the formula & $=\frac{\lambda}{C \rho}$ \\
\hline
\end{tabular}


There is some uncertainty in the dynamic strength numbers used in the calculations, which are the single most important piece of data to calculate drop height. Strength is a function of temperature and strain-rate. Historical data from Pantex report strain rates for the 11inch billet to be in the range $5-20 \mathrm{~m} / \mathrm{m} / \mathrm{s}$. The strengths used were chosen at an $\dot{\varepsilon}$ of 10 . While most of the data was measured at the chosen strain rate, there was some extrapolation required, particularly for X0234. The Hopkinson bar data ${ }^{(11)}$ for PBX 9404 and PBX 9011 are shown in Figures 7 \& 8.

Figure 7 Hopkinson Bar Data for PBX 9404

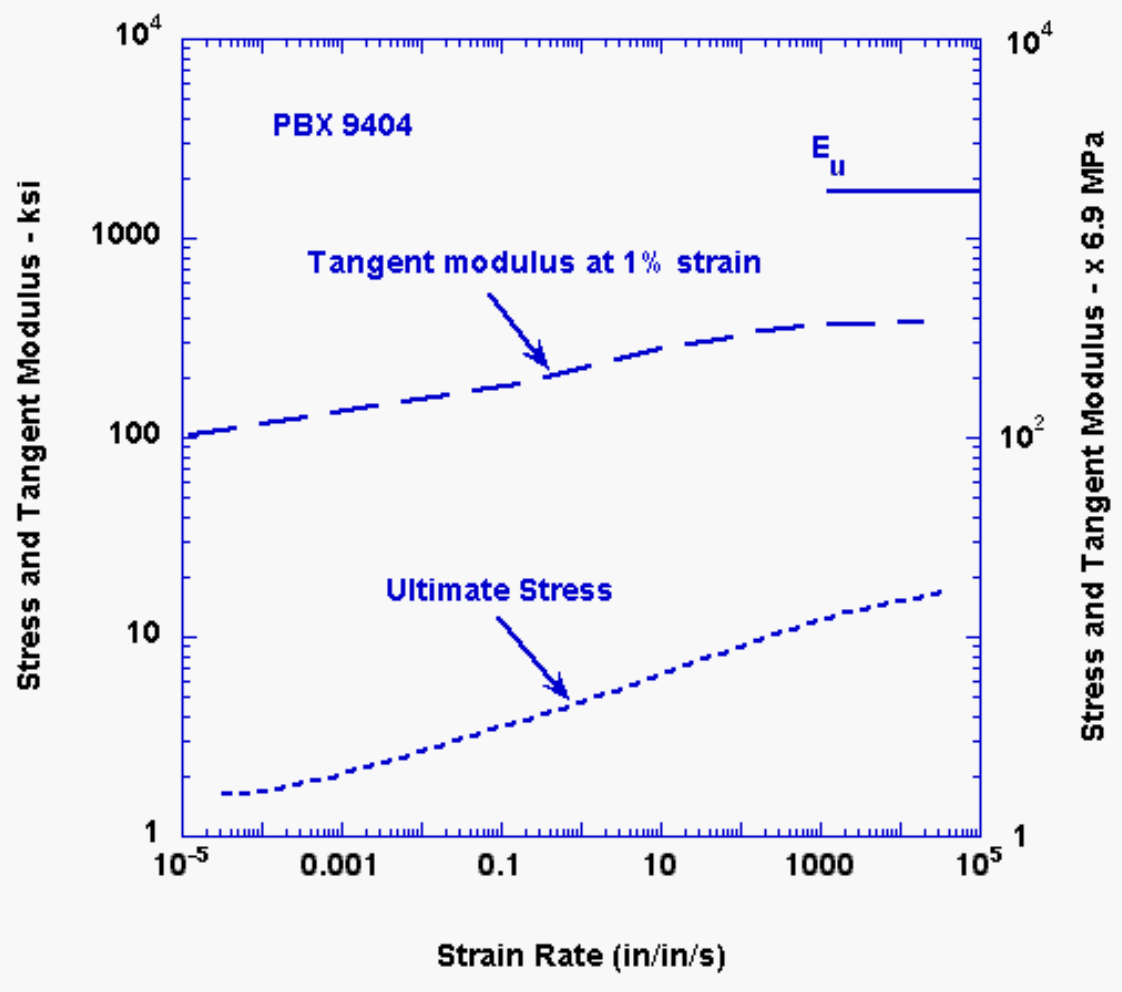


Figure 8 Hopkinson Bar Data for PBX 9011

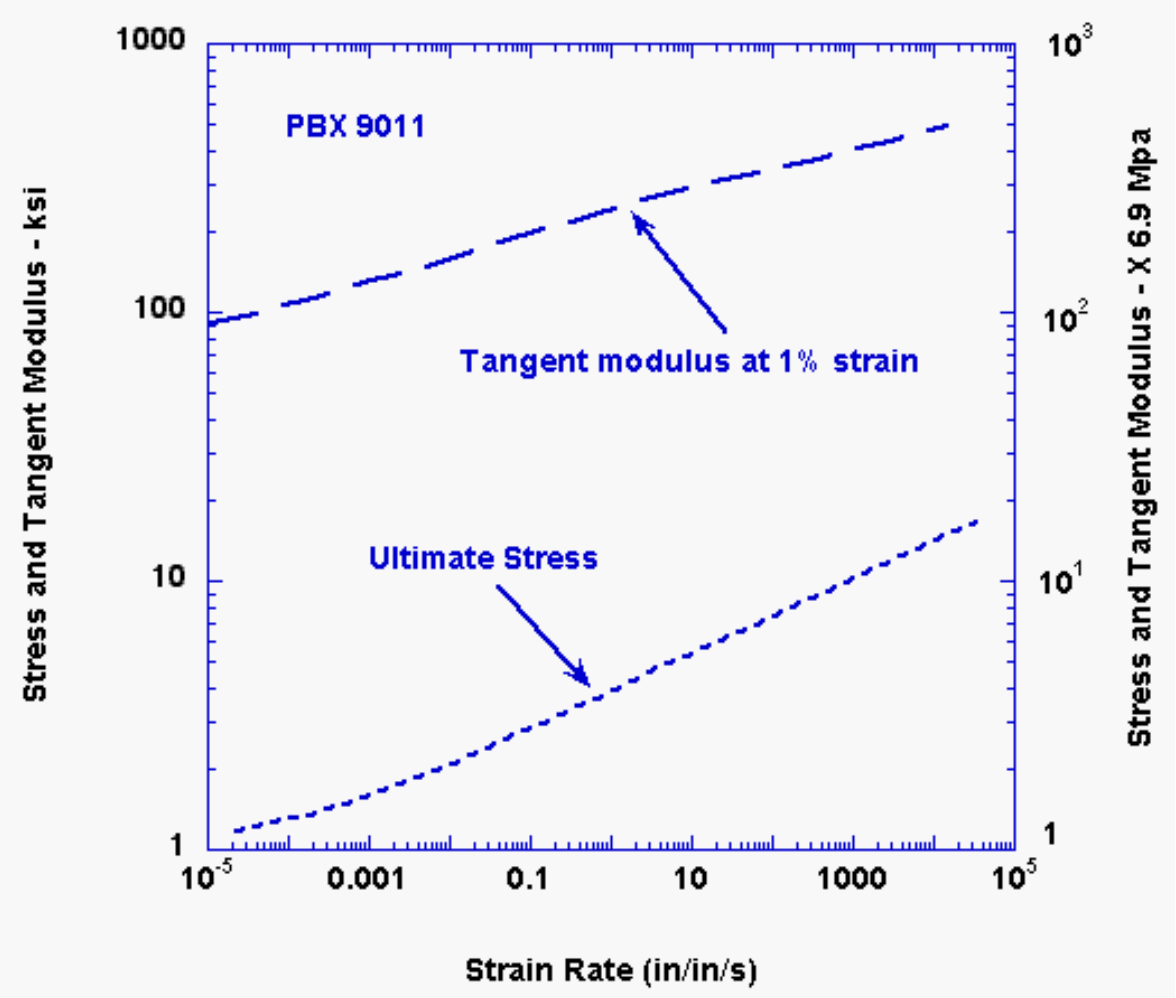

The LLNL explosive handbook provides a range of static and dynamic coefficients of friction based on material and target. For the purposes of demonstrating the effect of material strength, a single friction coefficient was chosen. The value of 0.4 appears to be reasonable for comparing the materials being calculated in the static range. This value has also been shown to be representative through measurements made by Green, Weston, Van Velkinburg ${ }^{(14)}$. They instrumented and filmed hemispheres that were dropped to gather accelerations for several HE materials. Their recorded values for coefficient of friction, as a function of time, for LX-04, LX-07, LX-09, PBX-9011 and PBX-9404 run 0.35 - 0.45. The shape factor discussed by Anderson, $\delta$, was chosen to be 0.2 as he proposed. One could probably quantify this better based upon thermal conductivities of the charge and target and the dynamic impact of the billet on the target. Obviously, these two parameters can be 
dialed in more accurately if one had better data. The chosen values are believed to be good choices for the stated purpose of this effort. The slab thickness (2a) for all the calculations was $0.1 \mathrm{~cm}$, or a half-slab thickness of $0.05 \mathrm{~cm}$. Since the impact area is $\sim 2.5 \mathrm{~cm}$. This is believed to represent a semi-infinite slab configuration since the aspect ratio is 50:1. The billet used for these calculations was 10 inches in diameter.

\section{DATA}

\section{SKID-TEST CALCUlations FOR HMX BASEd PBX MATERIALS}

An Excel spreadsheet was built to perform these calculations. The spreadsheet used a separate worksheet for each time step. There were approximately 15,000 calculations performed on each worksheet, to obtain the resolution necessary to observe the runaway thermal behavior. Because of memory limitations, the spreadsheet became slow after 12 time steps, so each step was determined by dividing the impact time (equation 8) by 12 . The computer used had a $1.2 \mathrm{Ghz}$ processor with $522 \mathrm{kB}$ of RAM. Each material required a separate spreadsheet, to perform the calculation to determine the temperature/time histories as a function of position. These data and the associated critical drop height are in Figures 9, 10, 11, 12, 13, and 14. Each of these Figures display 12 curves of temperature as a function of position; and each curve is a snapshot in time. Also noted on these plots is the drop height for which the calculation was performed. On the ordinate it can be easily seen what the initial temperature $\left({ }^{\circ} \mathrm{K}\right.$ ) for the drop conditions was calculated to be. All billets were started with an ambient temperature of $20{ }^{\circ} \mathrm{C}$. The time step used for each calculation can also be determined by differencing the times in the legend. The drop height was chosen by incrementally increasing the value until the temperature rise reached $700{ }^{\circ} \mathrm{K}$ during the time the billet is in contact with the target. The $700^{\circ} \mathrm{K}$ figure was chosen because of previously cited work that concludes hot spots must reach $\sim 430{ }^{\circ} \mathrm{C}$ to lead to a detonation. 


\section{PBX 9501 Drop Height CalCulation}

Figure 9 PBX 9501 Temperature time history

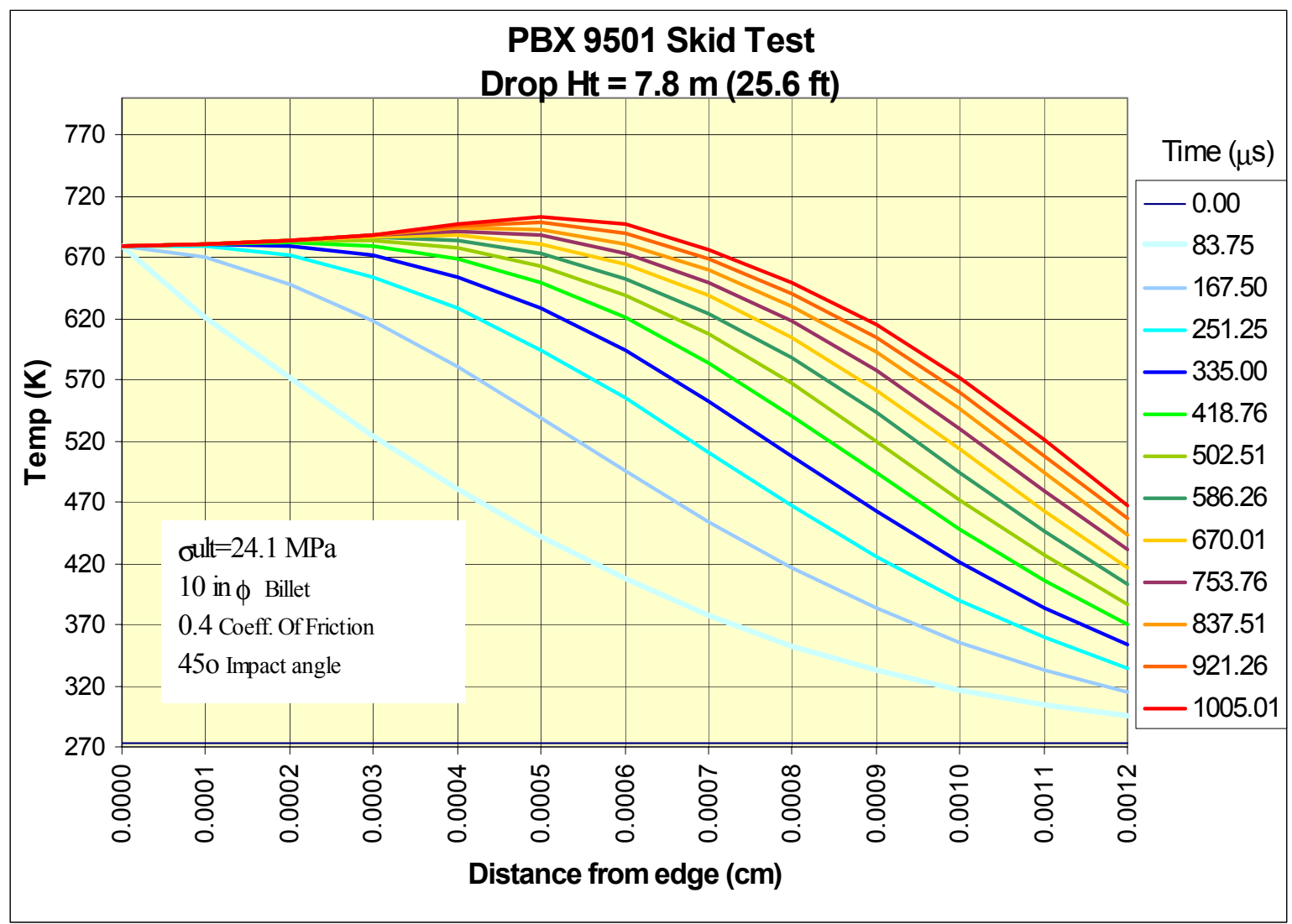




\section{PBX 9404 DROP HEIGHT CALCULATION}

Figure 10 PBX 9404 Temperature time history

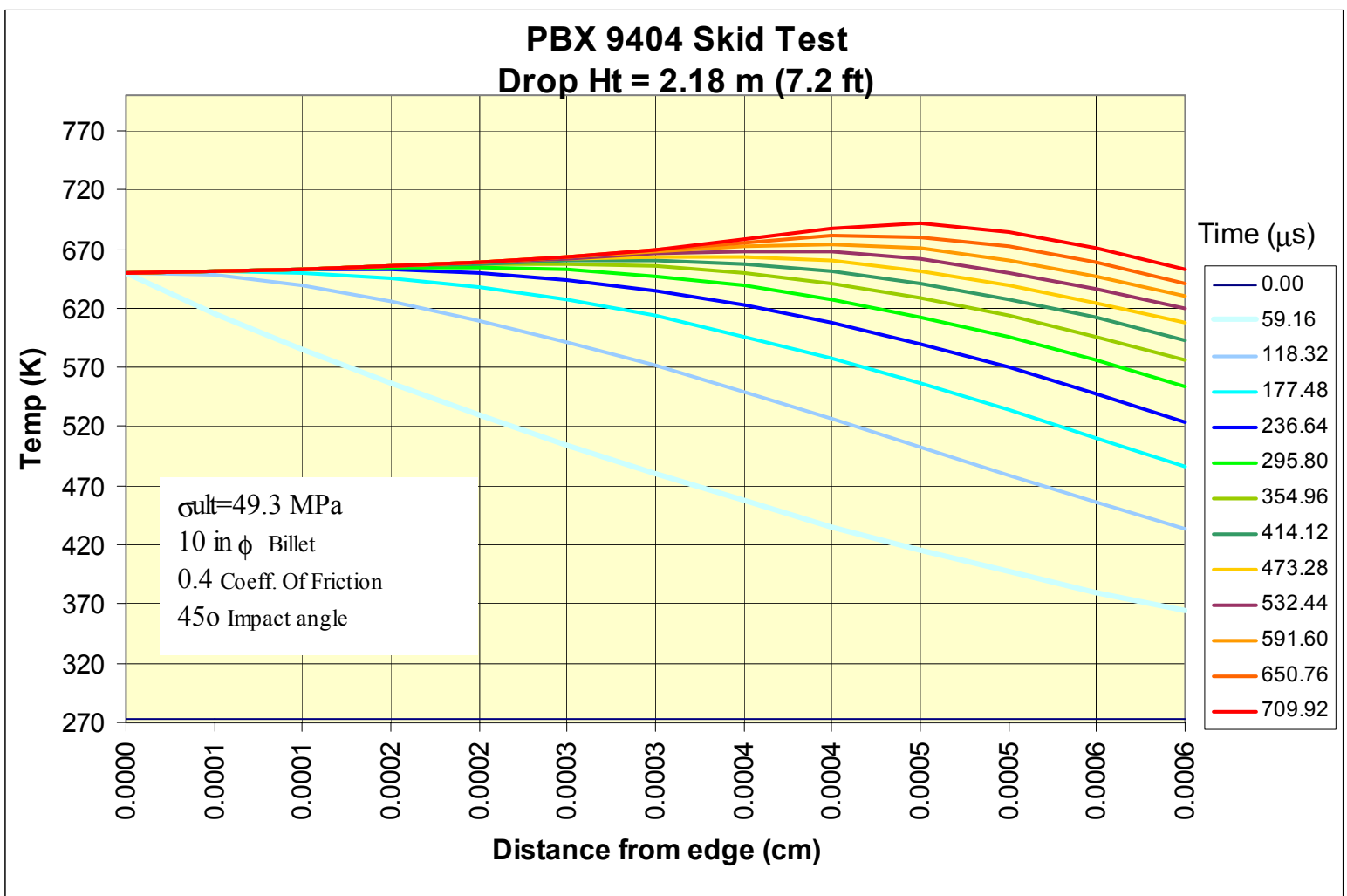




\section{LX-14 Drop Height CalCulation}

Figure 11 LX-14 Temperature time history

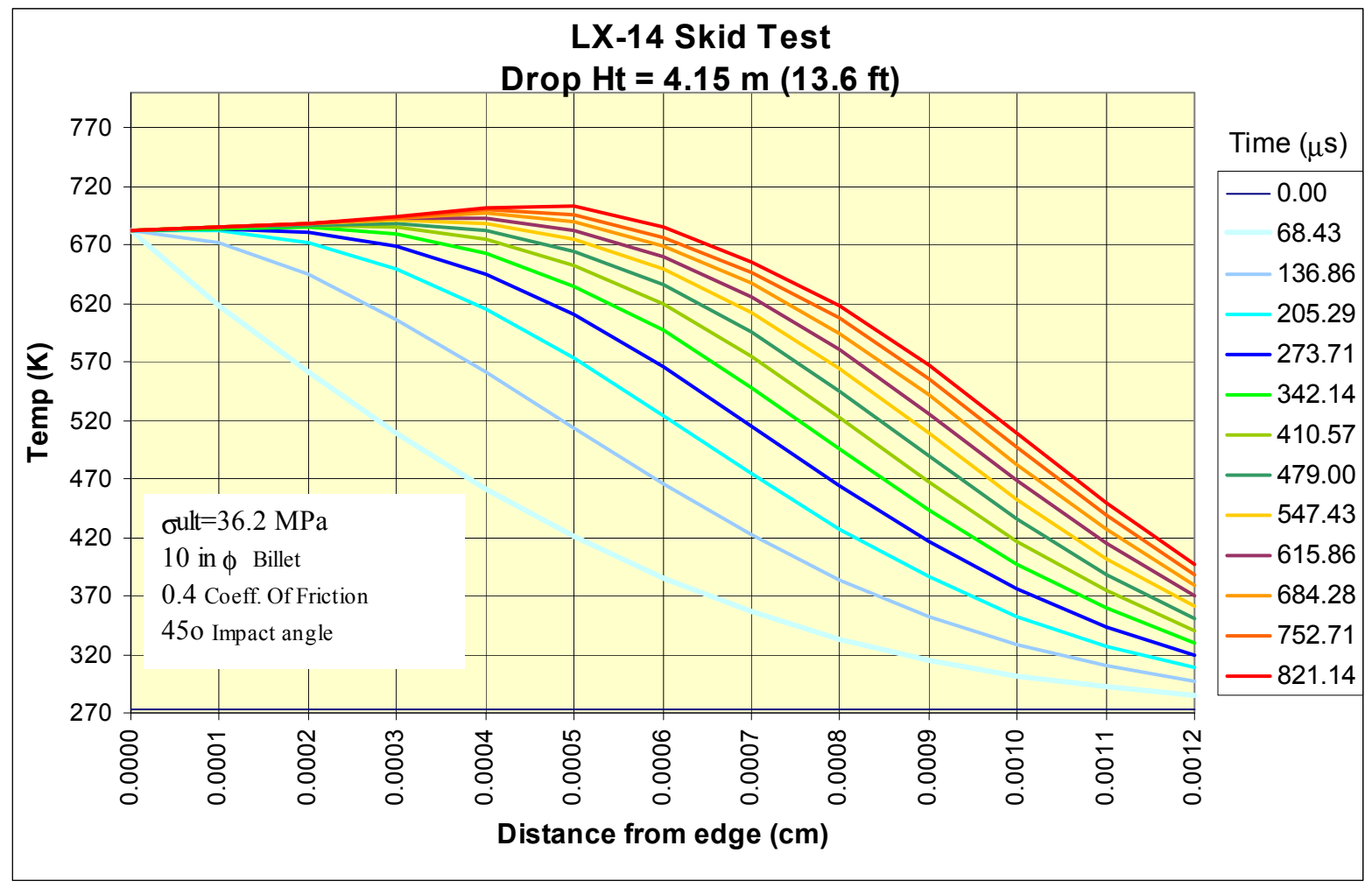




\section{PBX 9011 Drop Height CALCUlation}

Figure 12 PBX 9011 Temperature time history

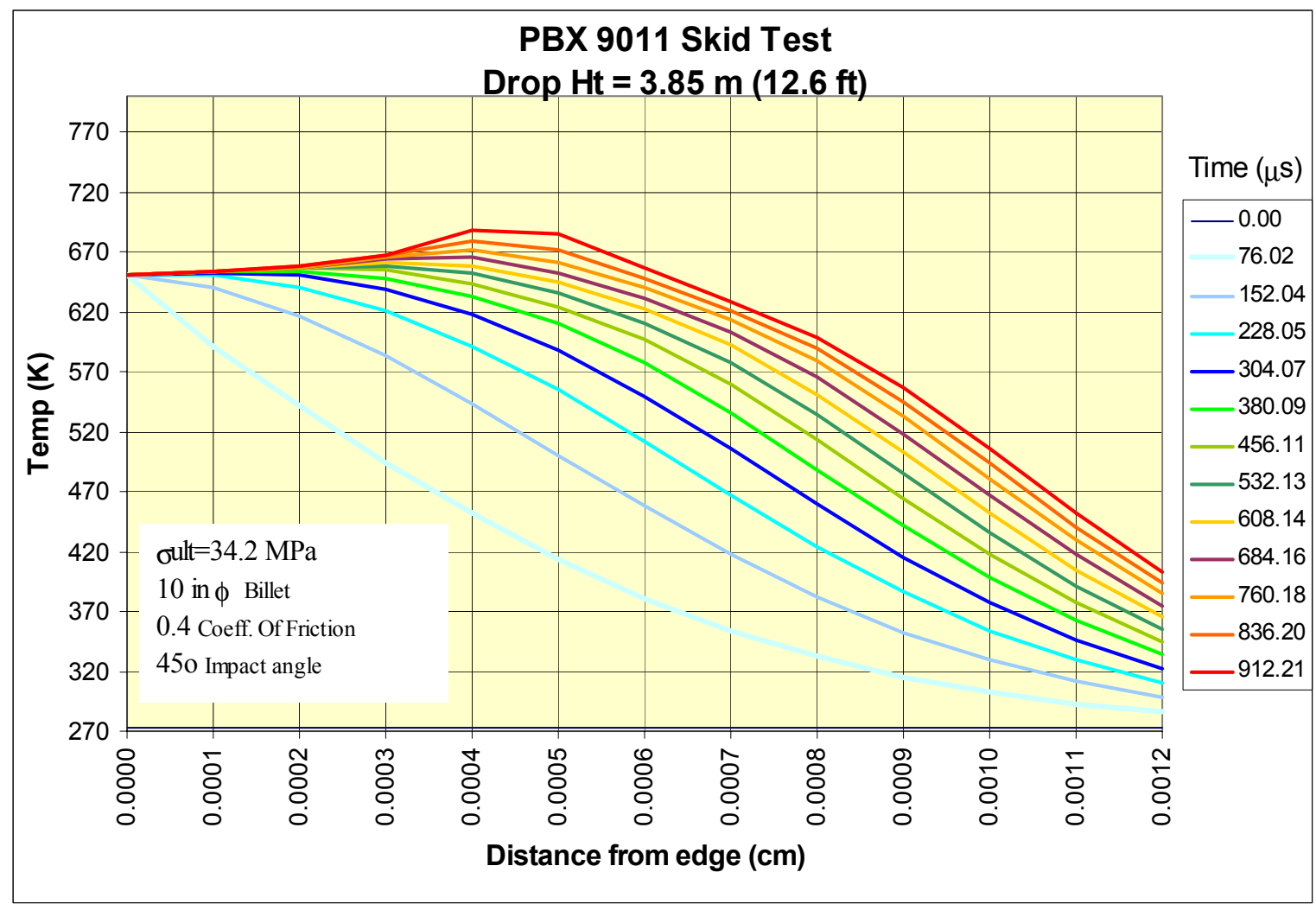




\section{X0234-94-20\% DROP HEIGHT CALCULATION}

Figure 13 X0234-94-20\% Temperature time history

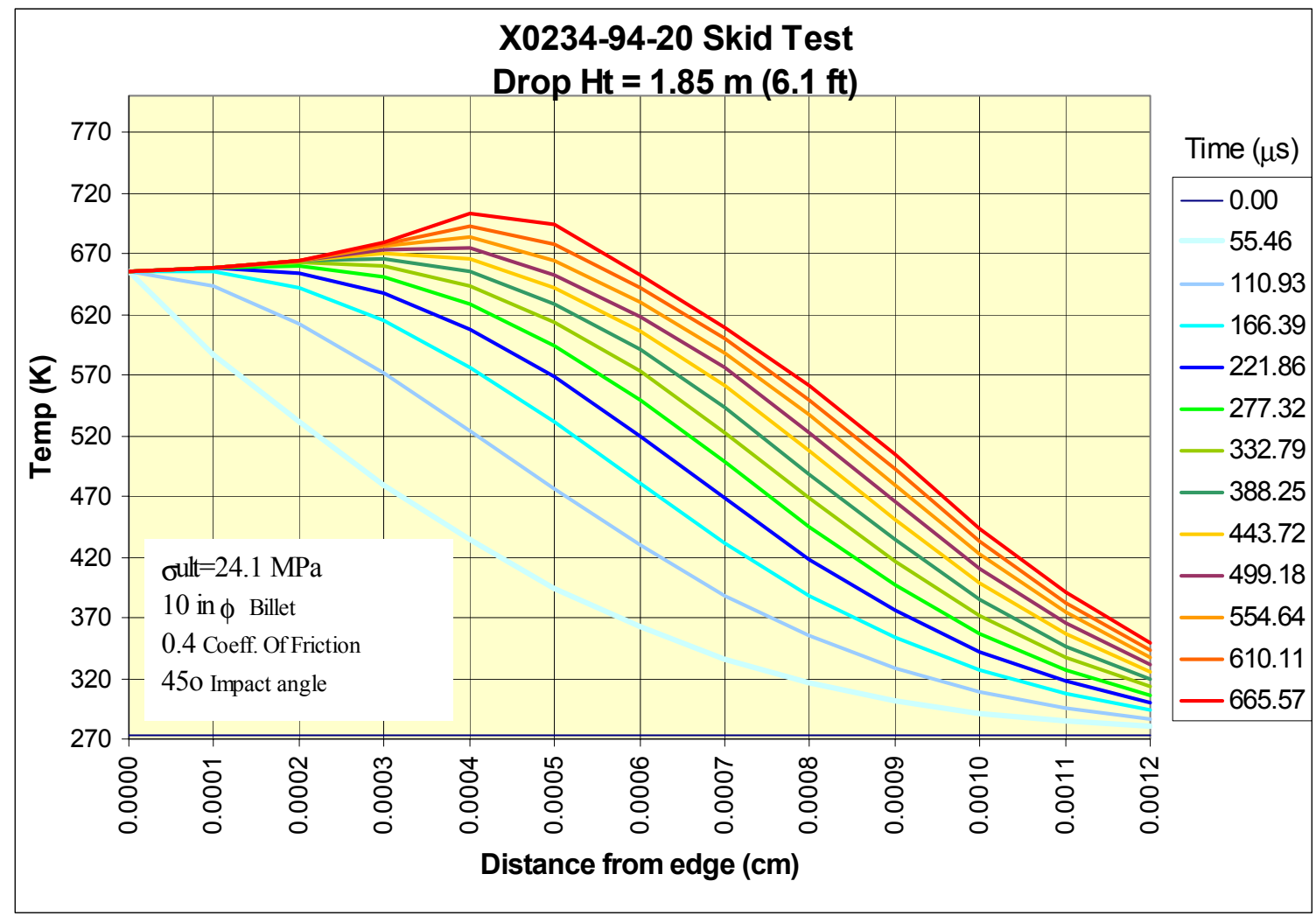




\section{X0234-94-50\% DROP HEIGHT CALCULATION}

Figure 14 X0234-94-50\% Temperature time history

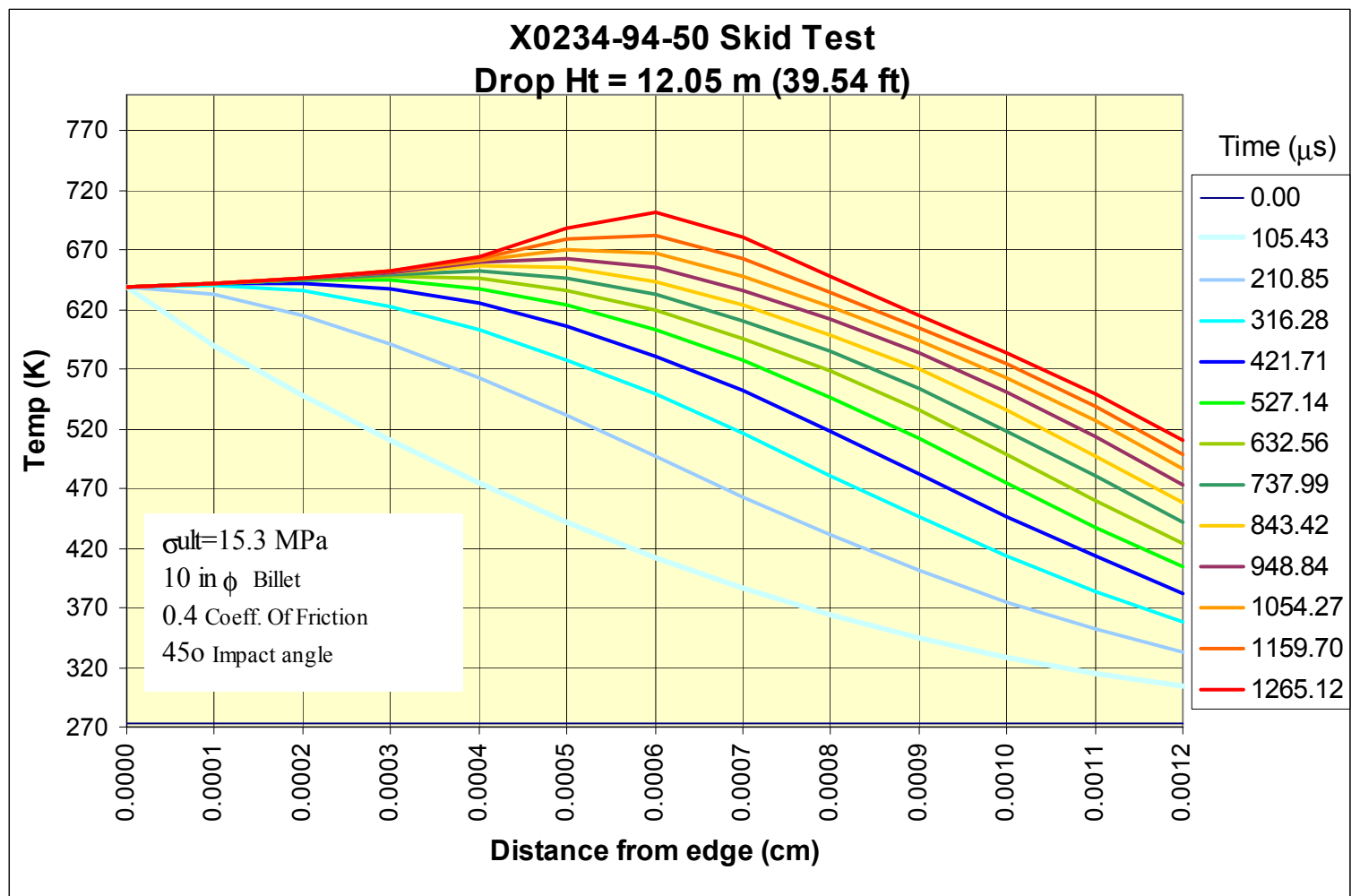

The drop heights calculated and shown in Figures 9-14 were then combined and graphed as drop height versus strength. This plot is shown in Figure 15. 


\section{CALCULATED DROP HEIGHT FOR ALL 6 MATERIALS}

Figure 15 Calculated Drop Heights for HMX Based PBXs

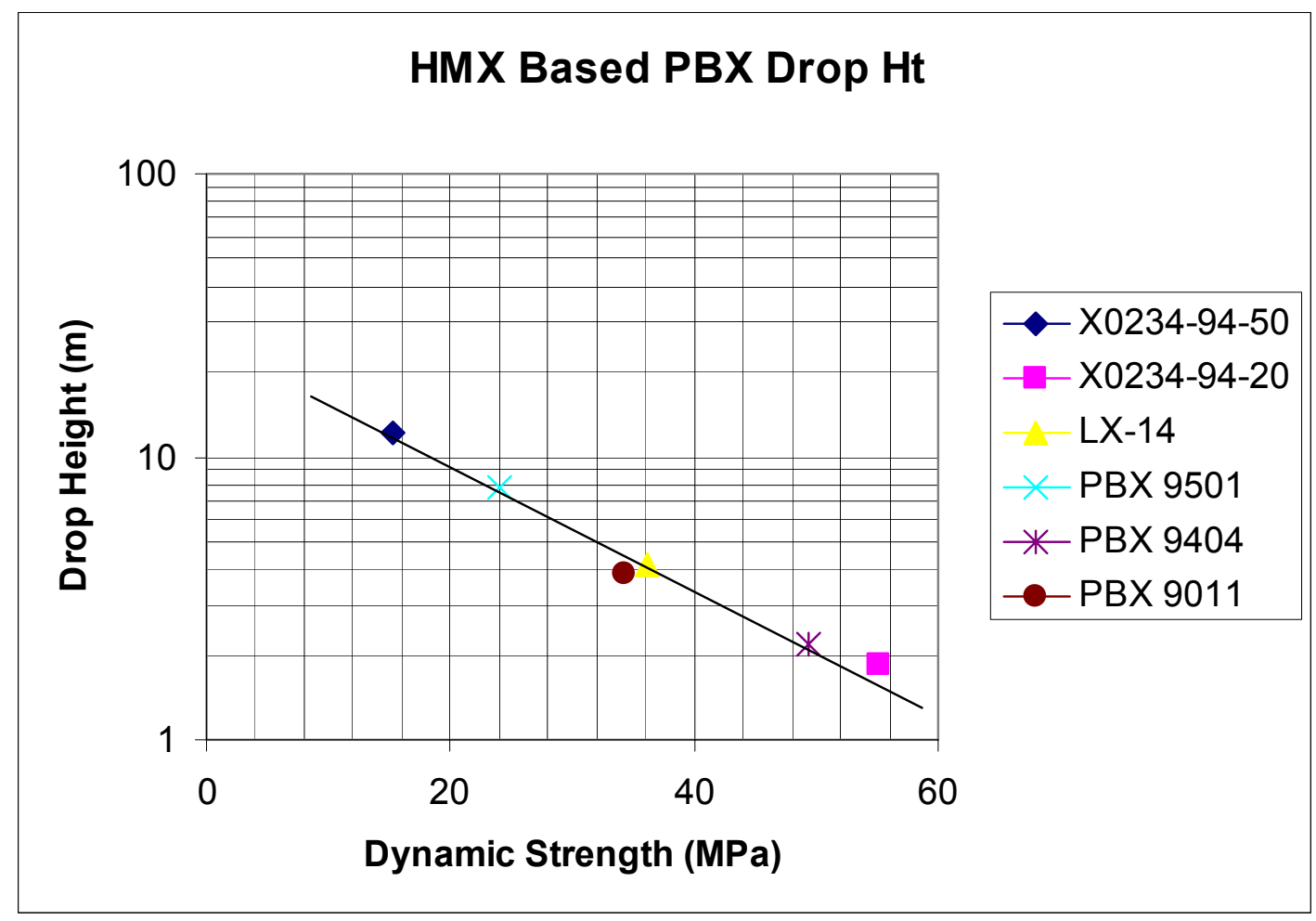

Note the linear behavior of these data on a log-log plot. While the units are different, the slope of this line is similar to that of Figure 5.

\section{CALCUlation OF DROP HEIGHT VERSUS BILLET WEIGHT}

To explore the effect of charge size on drop height, calculations were performed on PBX 9501 billets of varying size. A larger billet grows in mass and kinetic energy by the cube of the radius. Equation 22 shows that the temperature rise due to converting kinetic energy to heat is a function of charge velocity (drop height), billet mass, and mechanical properties. Figure 17 shows the calculated drop height for PBX 9501 as a function of charge diameter. Also shown is the velocity each charge will achieve for the given drop height. While the velocity appears to be a function of charge diameter, it is not. It is simply a function of drop height, which varies with charge diameter. 
Figure 16 Effect of Billet Size on Drop Height of PBX 9501

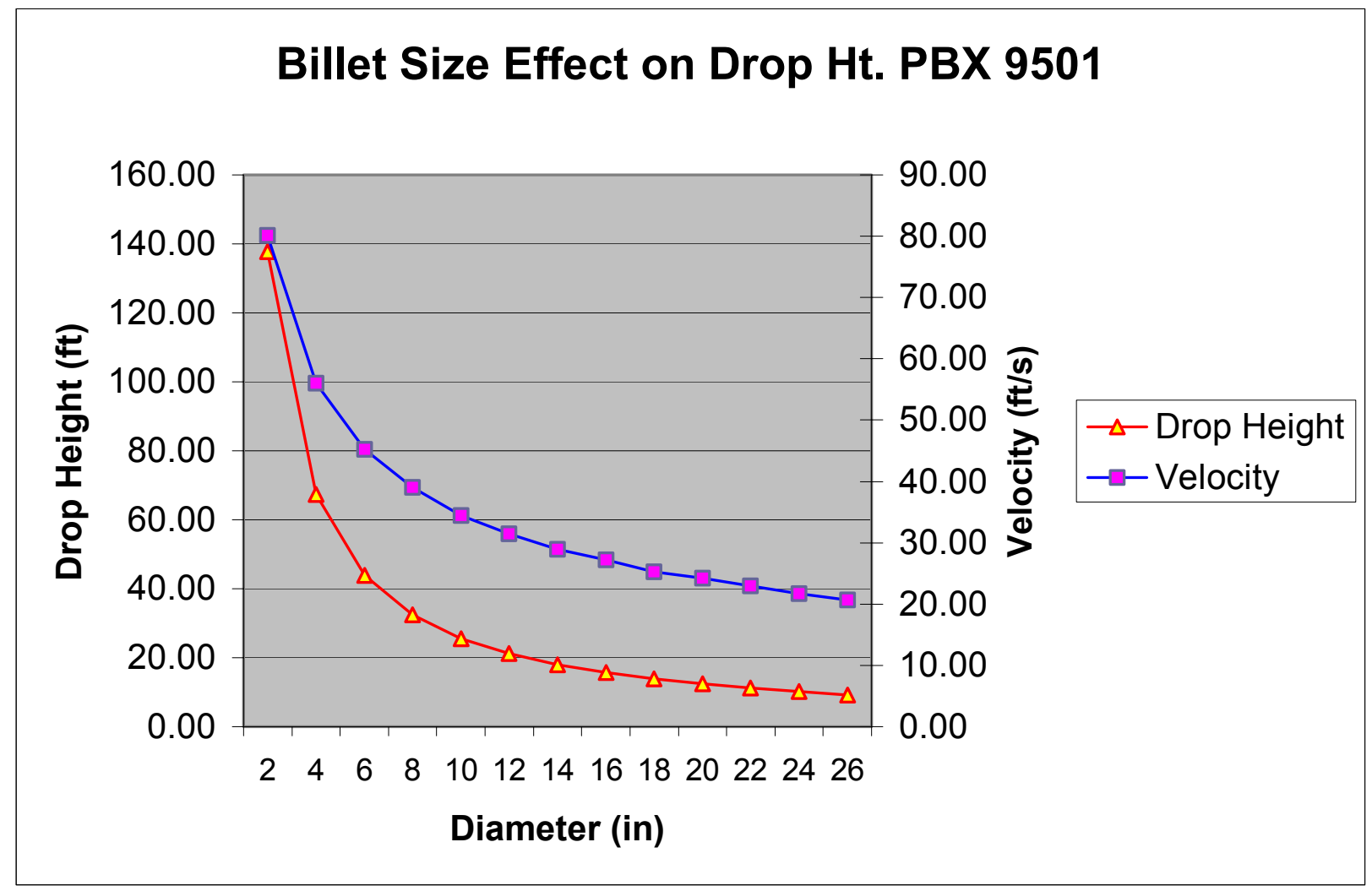

\section{MECHANICAL EXPERIMENTAL DATA FROM THE SKID-TEST}

Over the past three decades, the Pantex Plant has performed hundreds of instrumented skidtest experiments to understand the test and gather data on sensitivity of various formulations. J.H. Van Velkinburgh documents these tests in several reports. As an example of the data available, consider the reference 15 report. Figure 17 summarizes the mechanical behavior of PBX 9011, LX-14, and PBX 9404 as a function of drop height. These data were obtained for billets weighing $4.5 \mathrm{~kg}$ (8 in dia), whereas the calculations above were for billets $7.9 \mathrm{~kg}$ (10 in dia). This is a nice compendium showing, among other things, the spot size and strain rate of the impact event. 
Figure 17 Pantex Skid-test Mechanical Impact Data ${ }^{(15)}$

\begin{tabular}{|c|c|c|c|c|c|c|c|c|c|c|c|c|c|c|c|}
\hline $\begin{array}{l}\text { Drop } \\
\text { No. } \\
\end{array}$ & Material & $\begin{array}{l}\text { Drop } \\
\text { height } \\
\text { (ran) }\end{array}$ & $\begin{array}{l}\text { Billet } \\
\text { Weight } \\
(\mathrm{kg})\end{array}$ & $\begin{array}{c}\text { Contact } \\
\text { Spot } \\
\text { Diameter } \\
\text { (mm) } \\
\end{array}$ & COR & $k$ & $\begin{array}{r}\text { GRMS } \\
(\mathrm{MPa}) \\
\end{array}$ & $\begin{array}{r}\gamma \\
\text { (ms) } \\
\end{array}$ & $\underset{(\mathrm{mm})}{\mathrm{Zm}}$ & $\begin{array}{c}\mathrm{E} \\
(\mathrm{MPa}) \\
\end{array}$ & I & $\begin{array}{c}\varepsilon \\
(\mathrm{m} / \mathrm{m}) \\
\end{array}$ & $\begin{array}{c}\dot{\varepsilon} \\
(\mathrm{m} / \mathrm{m} / \mathrm{s})\end{array}$ & 6 & $\begin{array}{l}\text { NRMS } \\
(\mathrm{kn})\end{array}$ \\
\hline $\begin{array}{l}191 \\
192 \\
193 \\
194 \\
195 \\
196 \\
197 \\
198 \\
199 \\
200 \\
205 \\
204 \\
203 \\
202 \\
201 \\
206 \\
207 \\
208 \\
209 \\
210 \\
\end{array}$ & $\begin{array}{l}\text { PBX } 9011 \\
\text { PBX 9011 } \\
\text { PBX } 9011 \\
\text { PBX } 9011 \\
\text { PBX } 9011 \\
\text { LX-14 } \\
\text { LX-14 } \\
\text { LX-14 } \\
\text { LX-14 } \\
\text { LX-14 } \\
\text { LX-04 } \\
\text { LX-04 } \\
\text { LX-04 } \\
\text { LX-04 } \\
\text { LX-04 } \\
\text { PBX } 9404 \\
\text { PBX } 9404 \\
\text { PBX } 9404 \\
\text { PBX } 9404 \\
\text { PBX } 9404\end{array}$ & $\begin{array}{r}18.54 \\
38.61 \\
75.95 \\
305.00 \\
610.00 \\
18.80 \\
37.59 \\
76.71 \\
305.00 \\
610.00 \\
19.56 \\
38.61 \\
76.20 \\
305.00 \\
610.00 \\
19.30 \\
38.61 \\
75.69 \\
305.00 \\
610.00\end{array}$ & $\begin{array}{l}4.244 \\
4.277 \\
4.287 \\
4.283 \\
4.252 \\
4.410 \\
4.412 \\
4.410 \\
4.410 \\
4.411 \\
4.492 \\
4.492 \\
4.491 \\
4.493 \\
4.492 \\
4.432 \\
4.436 \\
4.432 \\
4.436 \\
4.436\end{array}$ & $\begin{array}{l}12.19 \\
13.72 \\
16.00 \\
21.08 \\
26.16 \\
10.92 \\
12.70 \\
13.97 \\
20.32 \\
24.13 \\
11.43 \\
13.46 \\
15.24 \\
20.57 \\
24.38 \\
10.41 \\
11.68 \\
13.72 \\
19.30 \\
22.86\end{array}$ & $\begin{array}{l}0.669 \\
0.708 \\
0.708 \\
0.682 \\
0.663 \\
0.731 \\
0.772 \\
0.745 \\
0.742 \\
0.744 \\
0.652 \\
0.596 \\
0.624 \\
0.615 \\
0.613 \\
0.733 \\
0.753 \\
0.764 \\
0.769 \\
0.872\end{array}$ & $\begin{array}{l}1.792 \\
1.921 \\
1.927 \\
1.742 \\
2.131 \\
1.416 \\
1.659 \\
1.426 \\
1.724 \\
1.926 \\
1.499 \\
1.758 \\
1.646 \\
1.646 \\
1.846 \\
1.540 \\
1.663 \\
1.619 \\
1.953 \\
1.905\end{array}$ & $\begin{array}{r}43.58 \\
60.58 \\
64.78 \\
80.16 \\
79.60 \\
58.55 \\
72.32 \\
86.28 \\
95.71 \\
105.82 \\
52.75 \\
60.89 \\
69.67 \\
85.05 \\
95.84 \\
81.43 \\
106.98 \\
107.34 \\
133.86 \\
139.76\end{array}$ & $\begin{array}{l}0.738 \\
0.613 \\
0.586 \\
0.554 \\
0.506 \\
0.726 \\
0.614 \\
0.596 \\
0.517 \\
0.468 \\
0.758 \\
0.662 \\
0.628 \\
0.567 \\
0.507 \\
0.589 \\
0.504 \\
0.499 \\
0.415 \\
0.413\end{array}$ & $\begin{array}{l}0.311 \\
0.367 \\
0.498 \\
0.956 \\
1.204 \\
0.316 \\
0.364 \\
0.513 \\
0.898 \\
1.133 \\
0.327 \\
0.386 \\
0.529 \\
0.964 \\
1.207 \\
0.264 \\
0.308 \\
0.435 \\
0.715 \\
1.028\end{array}$ & $\begin{array}{l}2744 \\
3607 \\
3452 \\
2823 \\
2905 \\
3073 \\
3832 \\
3458 \\
3585 \\
3853 \\
2644 \\
3010 \\
2953 \\
2742 \\
3031 \\
5425 \\
6314 \\
5630 \\
6378 \\
5800\end{array}$ & $\begin{array}{l}1.430 \\
1.452 \\
1.434 \\
1.416 \\
1.452 \\
1.396 \\
1.445 \\
1.424 \\
1.408 \\
1.426 \\
1.436 \\
1.489 \\
1.451 \\
1.436 \\
1.451 \\
1.373 \\
1.424 \\
1.396 \\
1.419 \\
1.389\end{array}$ & $\begin{array}{l}0.00297 \\
0.00350 \\
0.00475 \\
0.00913 \\
0.01149 \\
0.00301 \\
0.00348 \\
0.00490 \\
0.00857 \\
0.01081 \\
0.00312 \\
0.00369 \\
0.00505 \\
0.00920 \\
0.01152 \\
0.00252 \\
0.00294 \\
0.00416 \\
0.00682 \\
0.00981\end{array}$ & $\begin{array}{r}4.022 \\
5.716 \\
8.114 \\
16.457 \\
22.714 \\
4.148 \\
5.665 \\
8.214 \\
16.560 \\
23.126 \\
4.113 \\
5.572 \\
8.036 \\
16.238 \\
22.720 \\
4.274 \\
5.826 \\
8.322 \\
16.428 \\
23.736\end{array}$ & $\begin{array}{l}0.119 \\
0.103 \\
0.061 \\
0.098 \\
0.110 \\
0.036 \\
0.023 \\
0.077 \\
0.033 \\
0.038 \\
0.143 \\
0.169 \\
0.125 \\
0.118 \\
0.113 \\
0.067 \\
0.008 \\
0.000 \\
0.037 \\
0.032\end{array}$ & $\begin{array}{r}4.291 \\
7.514 \\
11.021 \\
24.381 \\
36.291 \\
4.768 \\
7.714 \\
11.211 \\
27.160 \\
41.910 \\
4.593 \\
7.030 \\
10.643 \\
24.154 \\
37.975 \\
6.118 \\
9.957 \\
13.759 \\
34.391 \\
51.655\end{array}$ \\
\hline $\begin{array}{r}\text { COR } \\
\text { OEA:S } \\
Y\end{array}$ & $\begin{array}{l}\text { Rus Flow } \\
\text { Compressi } \\
\text { Approach }\end{array}$ & $\begin{array}{l}\text { Time } \\
\text { Tims }\end{array}$ & ution & Billet & $\begin{aligned} Z m & = \\
E & = \\
I & = \\
\varepsilon & =\end{aligned}$ & $\begin{array}{l}\text { cimum B } \\
\text { astic P } \\
\text { act thw } \\
\text { arent }\end{array}$ & $\begin{array}{l}\text { aramete } \\
\text { mber } \\
\text { Contact }\end{array}$ & rach & & & $\begin{aligned} \dot{\varepsilon} & = \\
\theta & =1 \\
U S & =\end{aligned}$ & rent Co & $\begin{array}{l}\text { act Strain } \\
\text { Delay } \\
\text { ree }\end{array}$ & Rate & \\
\hline
\end{tabular}

\section{DISCUSSION}

The above calculations and experimental data clearly demonstrate the importance of dynamic strength on the skid sensitivity of a billet. The challenge in this work is finding accurate strengths at the "right" strain rate. Based on the data of Figure 17, the right strain rate appears to be in the range of $20-30 \mathrm{in} / \mathrm{in} / \mathrm{s}$. It is common knowledge that PBX composites have widely varying mechanical properties that are a function of temperature, rate, and load type (tension or compression). Zeroing in on the right value to perform calculations of this sort is difficult. In addition, kinetic material properties for PBXs are difficult to ascertain. For these reasons the calculations may not ever be a precise predictor of drop height for a new formulation. Many codes have been developed over the years that are better predictors of elusive quantity termed 50\% drop height. The intent of this work was to develop a code that captures the thermal kinetics as a function mechanical strength while varying mechanical energy input to the problem. The tool that was developed appears to work well for matching experimental drop heights for known materials and it 
demonstrates some very clear trends, that would help improve handling safety for new formulations.

Some of the trends noted in Figures $9-14$ are:

1. There is a distinct correlation between strength of the billet, time the billet is in contact with the target, and calculated drop height as shown in Table 3. There is a slight anomaly with PBX 9011, which may be attributable to the material properties used. The heat capacity, activation energy, and pre-exponential factor are noticeably higher than the other materials. This could be due to limited availability of material properties or the fact that PBX 9011 has 10\% binder where the others have 4.5-6\% binder. The rank ordering of experimental 50\% drop height data in Figure $2 \& 5$ are reasonably consistent with the calculations summarized in Figure 15. The most noticeable difference is the drop height for PBX 9011, which must be attributable to poor dynamic strength data.

Table 3

Impact Sensitivity Rank Ordering of HMX Based PBXs

\begin{tabular}{|l|c|c|c|c|}
\hline & $\begin{array}{c}\text { Strength } \\
\mathbf{( M p a )}\end{array}$ & $\begin{array}{c}\text { Impact } \\
\text { Duration (ms) }\end{array}$ & $\begin{array}{c}\text { Calculated Drop } \\
\text { Height (m) }\end{array}$ & $\begin{array}{c}\text { Expt'1 Drop } \\
\text { Height (m) }\end{array}$ \\
\hline X0234-94-50 & 15.3 & 1.27 & 12.05 & 10.7 \\
\hline PBX 9501 & 24.1 & 1.01 & 7.08 & 7.6 \\
\hline PBX 9011 & 34.2 & 0.91 & 3.85 & 23.8 \\
\hline LX-14 & 36.2 & 0.82 & 4.15 & 2.4 \\
\hline PBX 9404 & 49.3 & 0.71 & 2.18 & 0.6 \\
\hline X0234-94-20 & 55.1 & 0.67 & 1.85 & \\
\hline
\end{tabular}

2. Also compare the experimental values of dynamic flow stress shown in Figure 16 and compare them to those used in the calculations (Table 2). The relative order of strengths used in Table 2 and Figure 17 is the same. However, the flow stress $\left(\sigma_{\text {rms }}\right)$ from Figure 17 are roughly 3 times those used in the calculations. If these higher 
values were used in the calculations, the drop heights would rise substantially above experimental values. Additionally, the strengths used in Figure 5 are about 3-4 times those used in the calculations. As referenced earlier the values used come mostly from the LANL and LLNL explosive handbooks.

3. More effort could be invested in calculations using different values of $\mu$. The coefficient of friction (COF) of PBXs on sandpaper at the impact rates seen in the skid-test is not very well characterized. The value of 0.4 used in the calculations is probably a good general average, but matching strength and COF would be extremely important if the calculations were taken further. For instance, consider PBX 9501 where all things are held constant and the COF is varied in the range $0.3-$ 0.5. As already stated, the drop height with $\mathrm{COF}=0.4$ is $7.8 \mathrm{~m}$. Lowering $\mathrm{COF}$ to 0.3 increases the drop height to $14 \mathrm{~m}$. Increasing the COF to 0.5 lowers the drop height to $5 \mathrm{~m}$.

4. The $700{ }^{\circ} \mathrm{K}$ threshold used to determine detonation was chosen based on mature beliefs regarding hot-spot theory. This threshold, coupled with the handbook strengths used, seem to produce respectable values for drop heights.

5. Figure 16 demonstrates asymptotic behavior of drop height as a function of billet size. This demonstrates that the "standard" 10 in billet is only a snap shot. If one routinely works with larger billets, there could be a substantially lower drop height. For instance, with 9501 there is an approximate $8 \mathrm{ft}$ asymptote. The safe handling drop height then would be 26 feet for a 10 inch diameter hemisphere and only 8 feet for a $>24$ inch diameter hemisphere.

6. Calculations were also done for PBX 9501 dropped onto the $14^{\circ}$ Pantex target. This configuration creates more sliding and the height drops from 7.8 to $5.8 \mathrm{~m}$.

7. The point at which detonation occurs is interior to the billet. In all 6 cases, the detonation location is $\sim 0.0004 \mathrm{~cm}$ inside the impact surface. This is a result of the insulation effect and the reaction kinetics. The majority of HMX crystals in most of these formulations range in size from 1 - 100 microns. With the detonation location at 4 microns inside the charge, one might assume that the initiation occurs in the most exterior HMX crystal. On a micro scale, there are several crystals encapsulated 
in binder in the region of impact action. At this scale, the homogeneous properties used for these calculations are very much affected by the composite nature of the PBXs.

8. The experiments of Hatler et. al. showed that the drop heights can also be increased by dropping against a high conductivity target. These calculations can accommodate this physical change by changing the parameter, $\delta$. Considering target conductivity is really of theoretical interest since one cannot always choose the target upon which a charge is accidentally dropped. In many operating bays, the flooring is specifically chosen to increase the drop height required for initiation. A vinyl composite tile (VCT) is often used because of its compliance and thermal conductivity. Hatler et. al. ran experiments on 4 different target types, gold, aluminum-oxide $(0.51-0.89 \mu \mathrm{m})$, aluminum-oxide $(1.27-2.03 \mu \mathrm{m})$, and quartz. They found 50\% drop heights of $>46$ $\mathrm{m}, \sim 5.8 \mathrm{~m}, \sim 3.6 \mathrm{~m}$, and $0.55 \mathrm{~m}$, respectively. Conversely, one could work to lower the heat conduction of the composite HE. With additional effort, the calculations herein could be extended to different targets by partitioning heat flow, according to $\delta$, and correlating data to these experiments.

9. These calculations assume structural integrity of the charge. In some skid-test experiments, the charge breaks. A dynamic mechanical failure like this is difficult to calculate and is likely due to a manufacturing imperfection. Breakage is a localized stress relief for the impact area and generally will not detonate. Broken charges are not counted in a run of tests to determine $50 \%$ drop height.

\section{CONCLUSIONS}

The skid-test is primarily a tool to characterize how much kinetic energy (drop height) is required to create localized hot spots that cause detonation. Detonation in a skid-test is primarily a thermal ignition event. Upon impact, there is a partitioning of the energy in the form of heat, between conduction into charge, and conduction into the target. The impact of the charge on the target is a dynamic event, and the ability of the charge to deflect and 
create a larger contact area (spot size) allows for increased heat flow from the contact area to the target. Dissipation of heat into the target is a friend of a safer handling PBX material.

Since contact area is critical to the ability of a charge to dissipate thermal energy, the mechanical property of plastic flow stress becomes important to handling safety. The localized region of impact is very much outside the elastic region of the PBX stress strain response. The plastic flow stress of the PBX dictates spot size during impact. Experiments have shown that charges that are dropped, but do not detonate have a permanent spot of deformation. The higher the drop height, the larger the spot and the more energy there is to be dissipated. There is a point at which the energy to be dissipated overtakes the growth of the spot, and an energetic reaction ensues.

Experiments and calculations have shown that for materials with 95\% HMX and 5\% binder, the mechanical properties of the binder are extremely important to the $50 \%$ drop height of the material. In turn, the 50\% drop height represents the margin of handling safety available for consolidated PBX parts. If one were to create a new PBX composite, he would be well advised to consider more than matching the impedance of the polymer and the crystalline HE. In an ideal world, the binder would match the density of the explosive ( $\rho=1.840 \mathrm{~g} / \mathrm{cc}$ for $\alpha$ phase HMX), the thermal conductivity and dynamic flow stress would be low, and it would have a high strain to failure. Of course, the binder must be commercially available in large quantities from a reputable vendor. A binder of this nature would allow for a PBX composite that is both high performance and safe. Estane 5703 is not too far off from being an ideal binder, although research could turn up a better polymer.

When manufacturing charges in the 16 to 26 inch diameter range, serious consideration should be given to how the billets will be handled. Not only does the $50 \%$ drop height decrease, but the weight of these charges make handling by a single person irresponsible. The opportunity for a mistake when multiple people are handling large charges of HE raises concern. Charges of this size should be handled over appropriate flooring with consideration given to some sort of safety net or mechanical assistance.

The skid-test is a conservative measure of $50 \%$ drop height because of the sand paper used and the oblique, friction creating orientation. Dropping of charges on a flat operating bay floor, covered with a VCT tile, should be more forgiving than the results herein indicate. 
The calculations developed for this project, could certainly be improved by considering the partitioning of heat flow between the billet and target. In addition, there is tremendous opportunity to obtain much better data for: plastic flow stress at the right strain rates, coefficient of friction, and Arrhenius decomposition kinetic data for the various PBXs. 


\section{REFERENCES}

1. Crow, Edwin L., Davis, Francis A., Maxfield, Margaret W., "Statistics Manual, With Examples Taken From Ordnance Development," Dover Publications, NY, 1960.

2. Randolph, Alan D., Hatler, L.E., and Popolato, A., "Rapid Heating-to-Ignition of High Explosives. I. Friction Heating,” Ind. Eng. Chem., Fundam., Vol. 15, NO. 1, 1976.

3. Bowden, F.P., and Yoffe, A.D., Initiation and Growth of Explosion in Liquids and Solids, Cambridge, 1952.

4. Bowden, F.P., and Gurton, O.A., Nature, Lond., 162, 654, 1948.

5. Cooper, Paul W., Explosives Engineering, Wiley-VCH, 1996.

6. Mader, Charles L, Numerical Modeling of Explosives and Propellants, $2^{\text {nd }}$ Edition, CRC Press, 1998.

7. Beedham, K, Dyer, A.S., Holmes, W.I., "The Thermal Initiation and Growth of Reaction in Secondary Explosives under Transient Confinement," The $5^{\text {th }}$

Symposium on Detonation, Office of Naval Research, ACR-184, Pasadena, Calif., Aug, 1970.

8. Dyer, A.S., Taylor, J.W., "Initiation of Detonation by Friction on a High Explosive Charge," The $5^{\text {th }}$ Symposium on Detonation, Office of Naval Research, ACR-184, Pasadena, Calif., Aug, 1970.

9. LASL Memo, C.A. Anderson to A. Popolato, April 3, 1962.

10. UCRL-13284, "A Study of the Friction Ignition of a Spherical or Hemispherical Sample of Explosive Material in a Sliding Impact Skid-test", William M. Brobeck \& Associates Document No. 4500-95-6-R1, February, 1967.

11. Gibbs, Terry R., Popolato, Alphonse, LASL Explosive Property Data, University of California Press, 1980.

12. B.M. Dobratz, LLNL Explosives Handbook, Properties of Chemical Explosives and Explosive Simulants, UCRL52997, 1988.

13. LASL HED Process, Table 1.0 for X0234.

14. L. Green, A. Weston, J. Van Velkinburg, "Mechanical and Frictional Behavior of Skid-test Hemispherical Billets", UCRL-51085, Lawrence Livermore Laboratory, July 2, 1971.

15. J.H. Van Velkinburgh, "Mechanical and Frictional Behavior of $4.5 \mathrm{~kg}$ Skid-test Billets," MHSMP-75-24J, Normal Process Development Endeavor No. 216, April June 1975. 

This report has been reproduced directly from the best available copy. It is available electronically on the Web (http://www.doe.gov/bridge).

Copies are available for sale to U.S. Department of Energy employees and contractors from:

Office of Scientific and Technical Information P.O. Box 62

Oak Ridge, TN 37831

(865) 576-8401

Copies are available for sale to the public from: National Technical Information Service

U.S. Department of Commerce

5285 Port Royal Road

Springfield, VA 22161

(800) 553-6847 


\section{Los Alamos}

NATIONAL LABORATORY

EST.1943 